\title{
Gas Solubility in Ionic Liquids: UNIFAC-IL Model Extension
}

\section{Chen, Yuqiu; Liu, Xinyan; Woodley, John M.; Kontogeorgis, Georgios M.}

\section{Published in:}

Industrial and Engineering Chemistry Research

Link to article, DOI:

10.1021/acs.iecr.0c02769

Publication date:

2020

Document Version

Peer reviewed version

Link back to DTU Orbit

Citation (APA):

Chen, Y., Liu, X., Woodley, J. M., \& Kontogeorgis, G. M. (2020). Gas Solubility in lonic Liquids: UNIFAC-IL Model Extension. Industrial and Engineering Chemistry Research, 59(38), 16805-16821.

https://doi.org/10.1021/acs.iecr.0c02769

\section{General rights}

Copyright and moral rights for the publications made accessible in the public portal are retained by the authors and/or other copyright owners and it is a condition of accessing publications that users recognise and abide by the legal requirements associated with these rights.

- Users may download and print one copy of any publication from the public portal for the purpose of private study or research.

- You may not further distribute the material or use it for any profit-making activity or commercial gain

- You may freely distribute the URL identifying the publication in the public portal

If you believe that this document breaches copyright please contact us providing details, and we will remove access to the work immediately and investigate your claim 


\title{
Gas solubility in ionic liquids (ILs): UNIFAC-IL model extension
}

\author{
Yuqiu Chen a , Xinyan Liu ${ }^{\text {a,b }}$, John M. Woodley a , Georgios M. Kontogeorgis a,* \\ ${ }^{a}$ Department of Chemical and Biochemical Engineering, Technical University of Denmark \\ DK-2800 Lyngby, Denmark \\ ${ }^{\mathrm{b}}$ Beijing Key Laboratory of Ionic Liquids Clean Process, CAS Key Laboratory of Green Process and \\ Engineering, State Key Laboratory of Multiphase ComplexSystems, Institute of Process Engineering, \\ Chinese Academy of Sciences, Beijing, China
}

*Corresponding author. Tel.: +45 45252859. E-mail address: gk@kt.dtu.dk (G.M. Kontogeorgis)

\begin{abstract}
Prediction of thermodynamic behavior is essential for the early design stage of separation processes including solvent selection, process optimization and its performance evaluation. In order to better utilize ionic liquids (ILs) as solvents in gas separation processes, the UNIFAC-IL model of IL-liquid solute systems is extended to IL-gas systems by using experimental data from published works and pseudo-experimental data specifically generated from a calibrated COSMO-RS model. In this work, we consider in the model development a total number of 100 ILs from 6 cation families (i.e. imidazolium, pyridinium, pyrrolidinium, ammonium, phosphonium, guanidium) and 24 anion families (i.e. bis(trifluoromethanesulfonyl) amide, tetrafluoroborate, hexafluorophosphate, dimethylphosphate, heptafluorobutyrate, trifluoroacetate, trifluoromethanesulfonate, methylsulfonate, methylsulfate, ethylsulfate, nitrate, p-toluenesulfonate, 2-(2-methoxyethoxy)ethylsulfate, chloride, bromide, dicyanamide, tetracyanoborate, tris(pentafluoroethyl)trifluorophosphate, lactate, levulinate, saccharinate, succinamate, tetrafluoroethanesulfonate, bis(2,4,4-trime-thylpentyl)phosphinate), and 13 gases including $\mathrm{CO}_{2}, \mathrm{SO}_{2}, \mathrm{H}_{2} \mathrm{~S}, \mathrm{NH}_{3}, \mathrm{~N}_{2} \mathrm{O}, \mathrm{CO}, \mathrm{N}_{2}, \mathrm{O}_{2}, \mathrm{H}_{2}, \mathrm{CH}_{4}, \mathrm{C}_{2} \mathrm{H}_{4}, \mathrm{C}_{2} \mathrm{H}_{6}, \mathrm{C}_{3} \mathrm{H}_{8}$. The extended UNIFAC-IL-Gas model consists of two sub-models, namely the UNIFAC-IL-Gas (Exp.) model and the UNIFAC-IL-Gas (Pseudo-Exp.) model. The training and testing of the UNIFAC-IL-Gas (Exp.) model is based on $100 \%$ experimental data, while the training of the UNIFAC-IL-Gas (Pseudo-Exp.) model is based on pseudo-experimental data, but its testing is also based on $100 \%$ experimental data.
\end{abstract}

Keywords: Ionic liquids (ILs), gas solubility, UNIFAC-IL, COSMO-RS, pseudo-experimental data

\section{Introduction}

Unlike most conventional organic solvents, ionic liquids (ILs) are usually non-volatile, have good stability and possess tailor-made properties such as high solubility and selectivity ${ }^{1}$. For this reason, they have been considered as potential alternatives to volatile organic solvents in many separation processes including gas separation, ${ }^{2-5}$ extractive distillation ${ }^{5-10}$ and liquid-liquid extraction. ${ }^{11-15}$ In the past few decades, various ILs with different functions have been synthesized by combining different cations and anions. It has been found that some ILs have very distinct solvation capacities for different gases, indicating the high-potential of using ILs as solvents in gas separations. ${ }^{16}$ Meanwhile, work regarding the utilization of ILs as solvents in gas separation tasks from $\mathrm{CO}_{2}$ capture to shale gas purification have been widely studied. ${ }^{3-5,17-26}$

The performance of an IL-based gas separation process, as well as other solvent-based separation processes, largely depends on the solvent thermodynamic properties which are strongly determined by its molecular structure. Therefore, the selection of a suitable IL with desired thermodynamic properties for a specific gas separation task is of great importance. Considering that numerous ILs are possible composed of different cations and anions, the experimental trial and error method for IL screening is inevitably very time consuming and cost intensive, aside from being non-systematic. Therefore 
predictive thermodynamic models that can support efficient, cost-effective and systematic selection of ILs are highly desirable.

A reliable predictive thermodynamic model can both identify structure-property relationships and provide the phase equilibria information of the systems. By far, predictive thermodynamic models including activity coefficient models (e.g. NRTL, UNIQUAC, UNIFAC), ${ }^{27-35}$ equations of state models (e.g. GC EOS, CPA EOS, SAFT-based EOS) ${ }^{36-38}$ and Ab initio methods (e.g. COSMO-RS, COSMOSAC $)^{39-41}$ have been introduced to the IL containing systems. Most recently, Dong et al., proposed a united COSMO-UNIFAC model that combines COSMO-SAC and UNIFAC models for systems containing ILs. ${ }^{42,43}$ Among these thermodynamic models, COSMO-RS and UNIFAC are the two most commonly studied methods for modelling of IL-containing systems. The COSMO-RS model is a predictive method first proposed by Klamt and Eckert $(2000)^{44}$ and it only requires molecular structure information. Banerjee et al. (2006) ${ }^{45}$ used this model to predict binary VLE of systems containing imidazolium-based ILs and their work confirms that the presence of ILs in the vapor phase can be neglected even at very low pressures. Zhang et al. $(2008)^{17}$ applied the COSMO-RS model to predict the Henry's law constants of $\mathrm{CO}_{2}$ in $408 \mathrm{ILs}$ and it was found that ILs selected by this method present enhanced capability of capturing $\mathrm{CO}_{2}$, in contrast to ILs reported in literature. Based on the predicted selectivity and activity coefficient at infinite dilution using the COSMO-RS model, some suitable ILs are selected for extractive distillation processes and these screening ILs show better performance than their corresponding conventional solvents. ${ }^{40}$ Zhou et al. $(2012)^{46}$ used the COSMO-RS model to predict the mutual solubilities of 1500 ILs with water at $298.15 \mathrm{~K}$ and the influence of the types of anion and cation and substituent groups on the mutual solubility of IL-water was also investigated in their work. Although the use of COSMO-RS model does not require experimental information, it typically offers mostly qualitatively correct results. ${ }^{47} \mathrm{~A}$ way to improve the predictions from COSMO-RS is to use experimental data to calibrate the model and it is reported that all calibration models have better performance than the original COSMO-RS model. ${ }^{18,21,48-50}$

On the other hand, UNIFAC is usually preferred as it can provide reliable prediction results because the group interaction parameters in this model are regressed from experimental data. Additionally, UNIFAC is applicable for the thermodynamic prediction of those ILs for which experimental data is not unavailable, many of which may not even have been synthesized, although with potential practical application. Furthermore, UNIFAC can also be easily integrated into computer aided design methods (CAMD) ${ }^{51,52}$ which have been suggested as one of the most efficient and systematic approaches to IL screening. To date, hundreds of UNIFAC group interaction parameters covering various IL groups (i.e. cations, anions) and conventional functional groups have been presented. ${ }^{5,6,15,29,32,34,50}$ Kato and Gmehling ${ }^{29}$ studied the thermodynamic behavior of 119 IL-liquid solute systems using both the original and modified UNIFAC models and then Nebig and Gmehling ${ }^{53}$ revised and extended the modified UNIFAC model to the prediction of phase equilibria and excess properties for systems with ILs. The results show that the original UNIFAC especially modified UNIFAC method allows the reliable prediction of IL containing systems. Lei et al. (2009) ${ }^{28}$, Lei et al. (2012) ${ }^{34}$ and Roughton et al. (2012) extended the UNIFAC model to IL-solute systems by using different IL molecular decomposition methods. Since these extended UNIFAC-IL models can predict well the VLE of the systems with ILs, they can be used for screening/design suitable ILs for specific separation tasks. Most recently, Zhou et al. (2020) ${ }^{50}$ largely extended the UNIFAC model for IL-liquid solute systems by using experimental data collected from literature and computational data generated from calibrated COSMO-RS models. 
Remarkably, 39358 experimental data covering 21 conventional functional groups, 9 cation skeleton groups, and 29 anion groups was included in their work. In contrast, current UNIFAC-IL regression work of IL-gas systems is still limited to a few widely studied IL-CO systems $^{30,49,54}$ and a small number of other gases such as $\mathrm{H}_{2}$, and gaseous hydrocarbon systems. ${ }^{4,35,43,49,54,55}$ However, separation processes involving gases such as $\mathrm{H}_{2} \mathrm{~S}$ and $\mathrm{SO}_{2}$ are widely encountered in chemical and petrochemical industries, and therefore an extension of the UNIFAC-IL model to such IL-gas systems is highly desirable.

In the past decade, more and more solubility data of different gases in various ILs have been tested, which make it possible to extend the UNIFAC-IL model to their corresponding IL-gas systems. Although the solubility of $\mathrm{CO}_{2}$ in ILs has been widely studied, experimental data for other gases (e.g. $\mathrm{H}_{2} \mathrm{~S}, \mathrm{SO}_{2}$ ) in many ILs are still not available. Moreover, most solubility data for gases are limited to those ILs that are composed of well-known cations (i.e. imidazolium, pyridinium and ammonium) and anions (i.e. bis(trifluoromethylsulfonyl)imide, tetrafluoroborate and hexafluorophosphate). In order to extend the UNIFAC-IL model to those IL-gas systems which do not have experimental data, reliable computational data generated from a priori prediction methods must be supplemented. In this respect, one of the quantum chemical calculation-based models, COSMO-RS, has been successfully applied in the generation of computational data for many IL-solute systems. Nonetheless, COSMO-RS only offers qualitatively correct results in some cases due to the high deviation between experimental and COSMORS computational properties. For this reason, this model is usually calibrated or modified before its application so as to improve the reliability of these computational data. ${ }^{49,50}$

Based on the solubility database built by Lei et al., ${ }^{16}$ we develop in this work a new database combining experimental data and COSMO-RS data with the aim of achieving a systematic extension of the UNIFAC-IL model to IL-gas systems. Besides this database, a model extension strategy is also proposed in this work (see Section 3.1). Compared to the previously reported UNIFAC-IL model, the UNIFAC-IL-Gas model presented in this work covering many more IL-gas systems, and many ILs and gases is for the first time introduced to the UNIFAC-IL model. This extended UNIFAC-IL-Gas model can provide reliable predictions of gas solubility in ILs and it offers prospect of screening ILs for many gas separations prior to their corresponding experimental work. For example, the removal of acid gases especially $\mathrm{SO}_{2}$ and $\mathrm{H}_{2} \mathrm{~S}$ is critical in the natural gas upgrading process, but currently screening suitable ILs for this process is not possible due to the insufficient experimental data or the limitation of the current UNIFAC-IL model. Therefore, the UNIFAC-IL-Gas model proposed in this work is a solution in this direction. In most previous works, the IL-liquid solute system and IL-gas system are separately incorporated into the UNIFAC-IL-Gas model. In order to combine the IL-solute and IL-gas systems in a single UNIFAC-IL-Gas model, some interaction parameters between IL and conventional main groups regressed from IL- liquid solute systems by Roughton et al. ${ }^{6}$ have been adopted in this work. That is to say, this UNIFAC-IL-Gas model is not limited to IL-solute or IL-gas systems, but can be applied to IL-solute-gas systems, which is very important for the study of IL-based mixture solvent application in gas separation processes. In addition, the cation, anion and substituents of IL molecule are treated as separate functional groups in this work (see Section 3.2), which allows a larger and more flexible IL design space while using this UNIFAC-IL-Gas model.

\section{Thermodynamic models}

\subsection{The COSMO-RS model}

As a predictive thermodynamic model combining quantum chemical calculations and statistical thermodynamic approaches, COSMO-RS has been widely used to calculate the activity coefficients for many mixtures since it was first proposed by Klamt and Eckert. ${ }^{44}$ In this model, the activity coefficient of a compound $i$ in a solvent $S\left(\gamma_{S}{ }^{i}\right)$ is computed from the chemical potential of the pure compound $i$ $\left(\mu_{i}{ }^{i}\right)$ and the chemical potential of $i$ in the solvent $S\left(\mu_{S}{ }^{i}\right)$, as shown in Eq1. 


$$
\ln \gamma_{S}^{i}=\left(\mu_{S}^{i}+\mu_{i}^{i}\right) / R T
$$

where $\mu_{S}{ }^{i}$ can be calculated from the integration of the chemical potential of a surface segment $\sigma$ in the solvent $S\left(\mu_{S}(\sigma)\right)$ over the surface of the compound $i$ as follows.

$$
\mu_{S}^{i}=\mu_{C, S}{ }^{i}+\int p^{i}(\sigma) \mu_{S}(\sigma) d \sigma
$$

where $\mu_{C, S}{ }^{i}$ is a combinatorial term describing the size and shape differences of different molecules in the solvent. $p^{i}(\sigma)$ is a surface composition function (see Eq.3), also known as $\sigma$-profile, which represents the distribution of the polarization charges of each molecule and details of the relative amount of surface with polarity $\sigma$ on the surface of the molecule. $\mu_{S}(\sigma)$, i.e. $\sigma$-potential, as a measure of the affinity of the solvent $S$ to a surface of polarity $\sigma$, and is associated with the molecular surface interaction energies through a statistical thermodynamic procedure as described by Eqs.4-7.

$$
\begin{gathered}
p^{i}(\sigma)=\frac{n_{i(\sigma)}}{n_{i}}=\frac{A_{i(\sigma)}}{A_{i}} \\
\mu_{s}(\sigma)=-\frac{\mathrm{RT}}{a_{e f f}} \times \ln \left[\int p_{s}\left(\sigma^{\prime}\right) \exp \left\{\frac{a_{e f f}}{R T}\left(\mu_{s}\left(\sigma^{\prime}\right)-e\left(\sigma, \sigma^{\prime}\right)\right)\right\} d \sigma^{\prime}\right] \\
E_{\text {misfit }}\left(\sigma, \sigma^{\prime}\right)=a_{e f f} e_{m i s f i t}\left(\sigma, \sigma^{\prime}\right)=a_{e f f} \frac{\alpha^{\prime}}{2}\left(\sigma+\sigma^{\prime}\right)^{2} \\
E_{H B}\left(\sigma, \sigma^{\prime}\right)=a_{e f f} c_{H B} \min \left\{0, \min \left(0 ; \sigma_{\text {donor }}+\sigma_{H B}\right) \max \left(0 ; \sigma_{\text {acceptor }}-\sigma_{H B}\right)\right\} \\
E_{v d W}\left(\sigma, \sigma^{\prime}\right)=a_{e f f}\left(\tau_{v d W}+\tau^{\prime}{ }_{v d W}\right)
\end{gathered}
$$

In Eq.3, $n_{i(\sigma)}$ represents the number of segments with charge density $\sigma$ that have a surface area $A_{i(\sigma)}$, while $n_{i}$ represents the total number of segments in a single molecule with a total surface area $A_{i}$. In Eqs.4-7, $a_{e f f}$ is the effective contact area and $\alpha^{\prime}$ is an interaction parameter; interactions of electrostatics $\left(E_{\text {misfit }}\right)$ and hydrogen bonding $\left(E_{H B}\right)$ are described as functions of the polarization charges of two interacting surface segments $\sigma$ and $\sigma^{\prime}$. If the segments are located on a hydrogen bond donor or acceptor atom, these surface segments are expressed as $\sigma_{\text {donor }}$ and $\sigma_{\text {acceptor }} . c_{H B}$ and $\sigma_{H B}$ are adjustable parameters of the hydrogen bond strength and the threshold for hydrogen bonding, respectively. The less specific van der Waals $\left(E_{v d W}\right)$ interactions are also considered with the element specific $v d W$ interaction parameters $\tau_{v d W}$ and $\tau^{\prime}{ }_{v d W}$.

As described above, COSMO-RS is an a priori approach that can predict activity coefficients of compounds in liquid mixtures without experimental data as its calculation only relies on compounds' $\sigma$-profiles. To date, $\sigma$-profiles of many cations and anions of ILs, as well as thousands of conventional molecules, have been included in the COSMO-RS database. Moreover, the $\sigma$-profiles of those compounds not included can easily be derived from quantum chemical calculations. Since COSMORS allows efficient and fast thermodynamic calculations without experimental data, it has been applied to many liquids or liquid mixtures, especially for those systems for which experimental data is unavailable. For the same reason, the COSMO-RS model has also received attention for the prediction of gas solubility in ILs, where the ions are treated separately as an electroneutral mixture, and distinct COSMO files are generated. 


\subsection{The Original UNIFAC model}

Original UNIFAC proposed by Fredenslund et al., ${ }^{56}$ is a functional group based semi-empirical prediction method, where the activity coefficient for each species in the system is split into two components; a combinatorial $\gamma_{i}{ }^{C}$ and a residual component $\gamma_{i}{ }^{R}$. For the molecule $i$, the activity coefficients are broken down as:

$$
\ln \gamma_{i}=\ln \gamma_{i}^{C}+\ln \gamma_{i}^{R}
$$

The combinatorial component of the activity is related to the entropic effects accounting for the size and shape of molecules, which can be expressed via the van der Waals volume $\left(R_{k}\right)$ and surface area $\left(Q_{k}\right)$ parameters for each functional group. The residual component of the activity is due to energetic interactions between groups present in the system, and represents the enthalpy contribution. It can be expressed as binary interaction parameters $\left(\alpha_{n m}, \alpha_{m n}\right) \cdot \gamma_{i}{ }^{\mathrm{C}}$ and $\gamma_{i}{ }^{R}$ can be calculated by Eqs.9-13 and Eqs.14-19, respectively.

$$
\begin{gathered}
\ln \gamma_{i}{ }^{\mathrm{c}}=1-V_{i}+\ln V_{i}-5 q_{i}\left(1-\frac{V_{i}}{F_{i}}+\ln \left(\frac{V_{i}}{F_{i}}\right)\right) \\
F_{i}=\frac{q_{i}}{\sum_{j} q_{j} x_{j}} \\
V_{i}=\frac{r_{i}}{\sum_{j} r_{j} x_{j}} \\
q_{i}=\sum_{k} v_{k}{ }^{(i)} Q_{k} \\
r_{i}=\sum_{k} v_{k}{ }^{(i)} R_{k}
\end{gathered}
$$

where $F_{i}$ and $V_{i}$ represent auxiliary properties for component $i$; the pure component parameters $q_{i}$ and $r_{i}$, respectively, denote relative molecular van der Waals surface areas and molecular van der Waals volumes, which are obtained from the sum of the group area $Q_{k}$ and group volume parameters $R_{k}$, respectively. $v_{k}{ }^{(i)}$ is the number of groups of type $k$ in molecule $i$.

$$
\begin{gathered}
\ln \gamma_{i}^{R}=\sum_{k} v_{k}{ }^{(i)}\left(\ln \Gamma_{k}-\ln \Gamma_{k}{ }^{(i)}\right) \\
\ln \Gamma_{k}=Q_{k}\left(1-\ln \left(\sum_{m} \theta_{m} \psi_{m k}\right)-\sum_{m} \frac{\theta_{m} \psi_{k m}}{\sum_{n} \theta_{n} \psi_{n m}}\right. \\
\theta_{m}=\frac{Q_{m} X_{m}}{\sum_{n} Q_{n} X_{n}} \\
X_{m}=\frac{\sum_{i} v_{m}^{(i)} x_{i}}{\sum_{i} \sum_{k} v_{k}^{(i)} x_{i}} \\
\Psi_{n m}=\exp \left[-\left(\alpha_{n m} / T\right)\right] \\
\Psi_{m n}=\exp \left[-\left(\alpha_{m n} / T\right)\right]
\end{gathered}
$$

where $\Gamma_{k}$ and $\Gamma_{k}{ }^{(i)}$ denote the residual activity coefficient of group $\mathrm{k}$ and the residual activity coefficient of group $\mathrm{k}$ in pure component $\mathrm{i}$, respectively; $\theta_{m}$ is the fraction of group $\mathrm{m}$ in a mixture of the liquid phase and $X_{m} / X_{n}$ is the fraction of group $\mathrm{m}$ or $\mathrm{n}$ in the mixture; $\psi_{n m}$ and $\psi_{m n}$ are the group interaction parameters which can be calculated through Eqs.18 and 19 based on the value of UNIFAC group interaction parameters $\left(\alpha_{n m}, \alpha_{m n}\right)$ between groups $m$ and $n$.

Unlike COSMO-RS, the original UNIFAC model calculates the activity coefficient based on the van der Waals parameters (experiment-independent) of different functional subgroups and the binary interaction (experiment-dependent, temperature-independent) between the main groups of each component in the mixtures. Therefore, the predictive ability of the UNIFAC model is usually better than COSMO-RS, but its application, to some extent, is limited to systems where there are some available experimental data or parameters. Although the modified UNIFAC model ${ }^{57,58}$ with 
temperature-dependent interaction parameters has also been proposed because it can improve the model's prediction performance, the temperature has no noticeable impact on the activity coefficient for some IL-solute systems, especially IL-gas systems. For this reason, the original UNIFAC model is considered for the UNIFAC-IL model extension to IL-gas systems in this work. A large number of UNIFAC interaction parameters between conventional functional groups have been regressed and widely used. ${ }^{59,60}$

\section{UNIFAC-IL-Gas model extension}

3.1. Model extension strategy

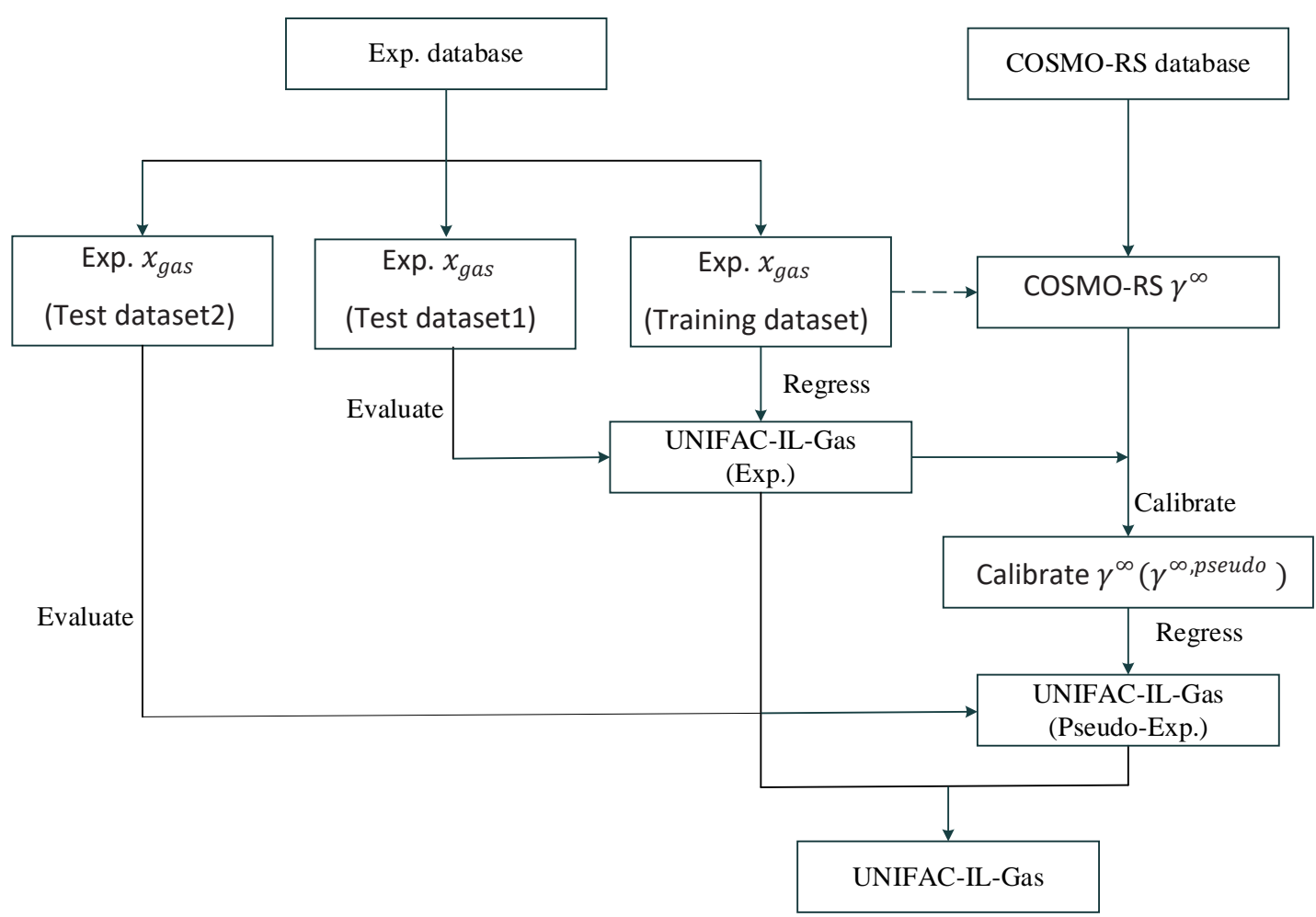

Figure 1. Hierarchical strategy for the extension of UNIFAC-IL-Gas model. (Exp. and Pseudo-Exp. indicate the source of data from experimental database and the calibrated COSMO-RS model)

Considering the large number of IL-gas systems in the UNIFAC-IL-Gas model extension, a hierarchical is proposed in this work (see Figure 1). Because testing is a very important part of the model extension, the experimental data coming from the Exp. database is divided into a training dataset and test datasets, and these datasets cover different IL-gas systems. Typically, 20-30\% of data points are used for testing purposes. However, considering the limited number of experimental data for some systems, the percentage of the test dataset used will be adjusted accordingly (see Section 4). First, the UNIFAC-IL model is extended to the IL-gas systems by using experimental gas solubility data (i.e. the training dataset) from Exp. database and this UNIFAC-IL-Gas (Exp.) model is evaluated by using experimental data of Test dataset1 from Exp. database. Secondly, a wide range of computational infinite dilution 
activity coefficients $\left(\gamma^{\infty}\right)$ of different gases in various ILs are specifically generated from COSMO-RS model, and then these $\gamma^{\infty}$ are calibrated by using calculated $\gamma^{\infty}$ from validated UNIFAC-IL-Gas (Exp.) model. Next, these calibrated $\gamma^{\infty}\left(\gamma^{\infty, p s e u d o}\right)$ are used for the regression of UNIFAC-IL-Gas (PseudoExp.) model and its predictive capability is further evaluated by using experimental data of Test dataset2 from Exp. database. Finally, an extended UNIFAC-IL-Gas model combining UNIFAC-IL-Gas (Exp.) and UNIFAC-IL-Gas (Pseudo-Exp.) model is obtained.

\subsection{Model extension method}

Since UNIFAC is a functional group based thermodynamic model, the IL molecule should be first decomposed appropriately into separate functional groups for the UNIFAC-IL model extension. The three main decomposition approaches generally used for this purpose are in Figure 2.

(I) The IL molecule is divided into one cation-based group and one anion group. This approach cannot reflect the structural variations of substituents in ILs.

(II) The IL molecule is divided into several groups, but the skeletons of the cation and anion are treated as a one functional group. This approach cannot be easily extended due to its fixed combination of cations and anions.

(III) The IL molecule is divided into several groups with the cation skeleton treated as a separate functional group. This approach enables the largest extension of the UNIFAC-IL model with an adequate consideration of the structural variation of cations, anions, and substituents in ILs. Meanwhile, it can significantly enlarge the design space and the flexibility for IL design in $\mathrm{CAMD}^{8,13}$. With these considerations, this decomposition approach is employed for both experimental data extension (Section 4.1) and pseudoexperimental data extension (Section 4.2) in this work.

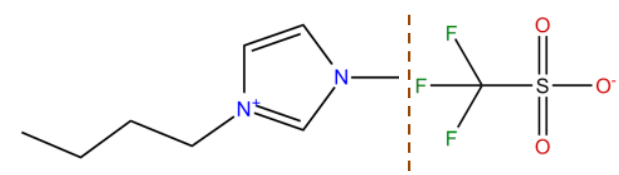

(I)

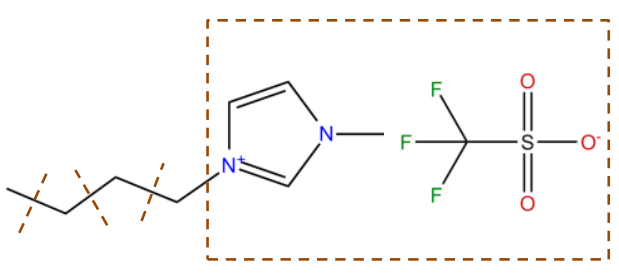

(II)

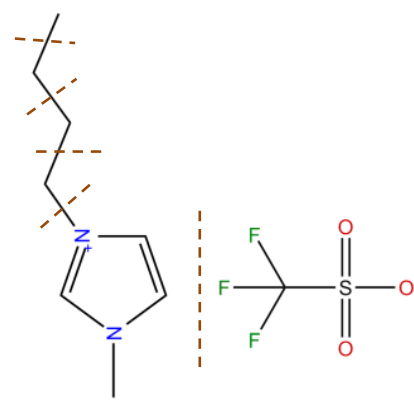

(III)

Figure 2. Three different decomposition approaches of IL for UNIFAC functional groups: Exemplified for1-butyl-3-methylimidazolium trifluoroacetate $\left(\left[\mathrm{C}_{4} \mathrm{mIm}\right]^{+}\left[\mathrm{CF}_{3} \mathrm{SO}_{3}\right]^{-}\right)$. Figure adapted from Chen et al. ${ }^{8}$.

Based on 13 studied gases, 7 cation groups, 24 anion groups and 3 substituent groups from the group decomposition are included in the proposed UNIFAC-IL model extension to IL-gas systems. The van der Waals volumes and areas $R_{k}$ and $Q_{k}$ of these groups are either taken from literature or calculated as follows: 


$$
\begin{aligned}
& R_{k}=\frac{V_{k} \times N_{A}}{V_{V W}} \\
& Q_{k}=\frac{A_{k} \times N_{A}}{A_{V W}}
\end{aligned}
$$

where $V_{k}$ and $A_{k}$ denote, respectively, the van der Waals group volumes and surface areas of group $k$ in each molecule, which can be calculated from correlations with molecular volumes and surface areas or from quantum chemical calculations. $N_{A}$ is the Avogadro's number with a value of $6.023 \times 10^{23} / \mathrm{mol}$, and $V_{V W}, A_{V W}$ are standard segment volume and surface area (of ethylene group in polyethylene) with values of $15.17 \mathrm{~cm}^{3} / \mathrm{mol}, 2.5 \times 10^{9} \mathrm{~cm}^{2} / \mathrm{mol}$, respectively. The values of $R_{k}$ and $Q_{k}$ for all the involved functional subgroups are summarized in Table 1. Most of the $R_{k}$ and $Q_{k}$ values are taken from previously published work and the remaining parameters obtained in this work are calculated from COSMO-RS.

Table 1: Group's information of $R_{k}$ and $Q_{k}$ involved in the extension of the UNIFAC-IL-Gas model

\begin{tabular}{|c|c|c|c|c|c|c|}
\hline Group No. & Main group & Subgroup & $\mathrm{R}_{\mathrm{k}}$ & $\mathrm{Q}_{\mathrm{k}}$ & Reference & Structure \\
\hline 1 & $\mathrm{CO}_{2}$ & $\mathrm{CO}_{2}$ & 1.3000 & 1.1200 & 61 & \\
\hline 2 & $\mathrm{SO}_{2}$ & $\mathrm{SO}_{2}$ & 0.9011 & 0.8480 & 54 & \\
\hline 3 & $\mathrm{H}_{2} \mathrm{~S}$ & $\mathrm{H}_{2} \mathrm{~S}$ & 1.7933 & 1.5022 & This work & \\
\hline 4 & $\mathrm{NH}_{3}$ & $\mathrm{NH}_{3}$ & 1.2193 & 1.1786 & This work & \\
\hline 5 & $\mathrm{~N}_{2} \mathrm{O}$ & $\mathrm{N}_{2} \mathrm{O}$ & 1.8465 & 1.5860 & This work & \\
\hline 6 & $\mathrm{CO}$ & $\mathrm{CO}$ & 1.0470 & 1.0600 & 35 & \\
\hline 7 & $\mathrm{~N}_{2}$ & $\mathrm{~N}_{2}$ & 0.9340 & 0.9750 & 4 & \\
\hline 8 & $\mathrm{O}_{2}$ & $\mathrm{O}_{2}$ & 1.1257 & 1.1940 & 4 & \\
\hline 9 & $\mathrm{H}_{2}$ & $\mathrm{H}_{2}$ & 0.528 & 0.664 & 35 & \\
\hline 10 & $\mathrm{CH}_{4}$ & $\mathrm{CH}_{4}$ & 1.1290 & 1.1240 & 61 & \\
\hline 11 & $\mathrm{C}_{2} \mathrm{H}_{4}$ & $\mathrm{C}_{2} \mathrm{H}_{4}$ & 1.5740 & 1.4880 & 61 & \\
\hline 12 & $\mathrm{C}_{2} \mathrm{H}_{6}$ & $\mathrm{C}_{2} \mathrm{H}_{6}$ & 1.8022 & 1.6960 & 62 & \\
\hline 13 & $\mathrm{C}_{3} \mathrm{H}_{8}$ & $\mathrm{C}_{3} \mathrm{H}_{8}$ & 3.2002 & 2.3460 & This work & \\
\hline \multirow[t]{3}{*}{14} & $\mathrm{CH}_{2}$ & $\mathrm{CH}_{3}$ & 0.9011 & 0.8480 & 56 & \\
\hline & & $\mathrm{CH}_{2}$ & 0.6744 & 0.5400 & 56 & \\
\hline & & $\mathrm{CH}$ & 0.4469 & 0.228 & 56 & \\
\hline 15 & $\mathrm{OH}$ & $\mathrm{OH}$ & 1.0000 & 1.200 & 59 & \\
\hline \multirow[t]{2}{*}{16} & $\mathrm{CH}_{2} \mathrm{O}$ & $\mathrm{CH}_{3} \mathrm{O}$ & 1.1450 & 1.088 & 28 & \\
\hline & & $\mathrm{CH}_{2} \mathrm{O}$ & 0.9183 & 0.7800 & 28 & \\
\hline \multirow[t]{2}{*}{17} & {$[\mathrm{Im}]$} & [Im] & 1.9471 & 0.8660 & 6 & \\
\hline & & [mIm] & 2.8482 & 1.7140 & 6 & \\
\hline 18 & [Py] & {$[\mathrm{Py}]$} & 2.6670 & 1.5530 & 6 & \\
\hline
\end{tabular}
( $R_{k}$ and $Q_{k}$ obtained in this work are calculated from COSMO-RS) 


\begin{tabular}{|c|c|c|c|c|c|c|}
\hline & & [mPy] & 3.5681 & 2.4010 & 6 & \\
\hline 19 & [Pyr] & [mPyr] & 3.3873 & 2.9093 & 6 & \\
\hline \multirow[t]{4}{*}{20} & {$[\mathrm{~N}]$} & {$\left[\mathrm{CH}_{3} \mathrm{~N}\right]$} & 1.1865 & 0.9400 & 6 & \\
\hline & & {$\left[\mathrm{C}_{2} \mathrm{H}_{5} \mathrm{~N}\right]$} & 1.8609 & 1.4800 & 6 & \\
\hline & & {$\left[\mathrm{C}_{3} \mathrm{H}_{7} \mathrm{~N}\right]$} & 2.5353 & 2.0200 & 6 & \\
\hline & & {$\left[\mathrm{C}_{4} \mathrm{H}_{9} \mathrm{~N}\right]$} & 3.2097 & 2.5600 & 6 & \\
\hline 21 & {$[\mathrm{P}]$} & {$\left[\mathrm{CH}_{3} \mathrm{P}\right]$} & 1.4931 & 0.9197 & 50 & \\
\hline 22 & [TDPh] & [TDPh] & 29.7600 & 16.1100 & This work & \\
\hline 23 & [TMG] & [TMG] & 3.2002 & 2.3459 & This work & \\
\hline 24 & {$\left[\mathrm{Tf}_{2} \mathrm{~N}\right]$} & {$\left[\mathrm{Tf}_{2} \mathrm{~N}\right]$} & 5.7738 & 4.9320 & 6 & \\
\hline 25 & {$\left[\mathrm{BF}_{4}\right]$} & {$\left[\mathrm{BF}_{4}\right]$} & 1.7856 & 1.4940 & 6 & \\
\hline 26 & {$\left[\mathrm{PF}_{6}\right]$} & {$\left[\mathrm{PF}_{6}\right]$} & 7.0615 & 6.5787 & 6 & \\
\hline 27 & [DMP] & [DMP] & 3.4127 & 3.2820 & 6 & $\mathrm{H}_{3} \mathrm{C}-\mathrm{O}-\mathrm{P}$ \\
\hline 28 & {$\left[\mathrm{C}_{3} \mathrm{~F}_{7} \mathrm{CO}_{2}\right]$} & {$\left[\mathrm{C}_{3} \mathrm{~F}_{7} \mathrm{COO}\right]$} & 6.7579 & 3.9692 & This work & \\
\hline 29 & [TFA] & {$\left[\mathrm{CF}_{3} \mathrm{COO}\right]$} & 3.1773 & 3.2200 & 6 & \\
\hline
\end{tabular}




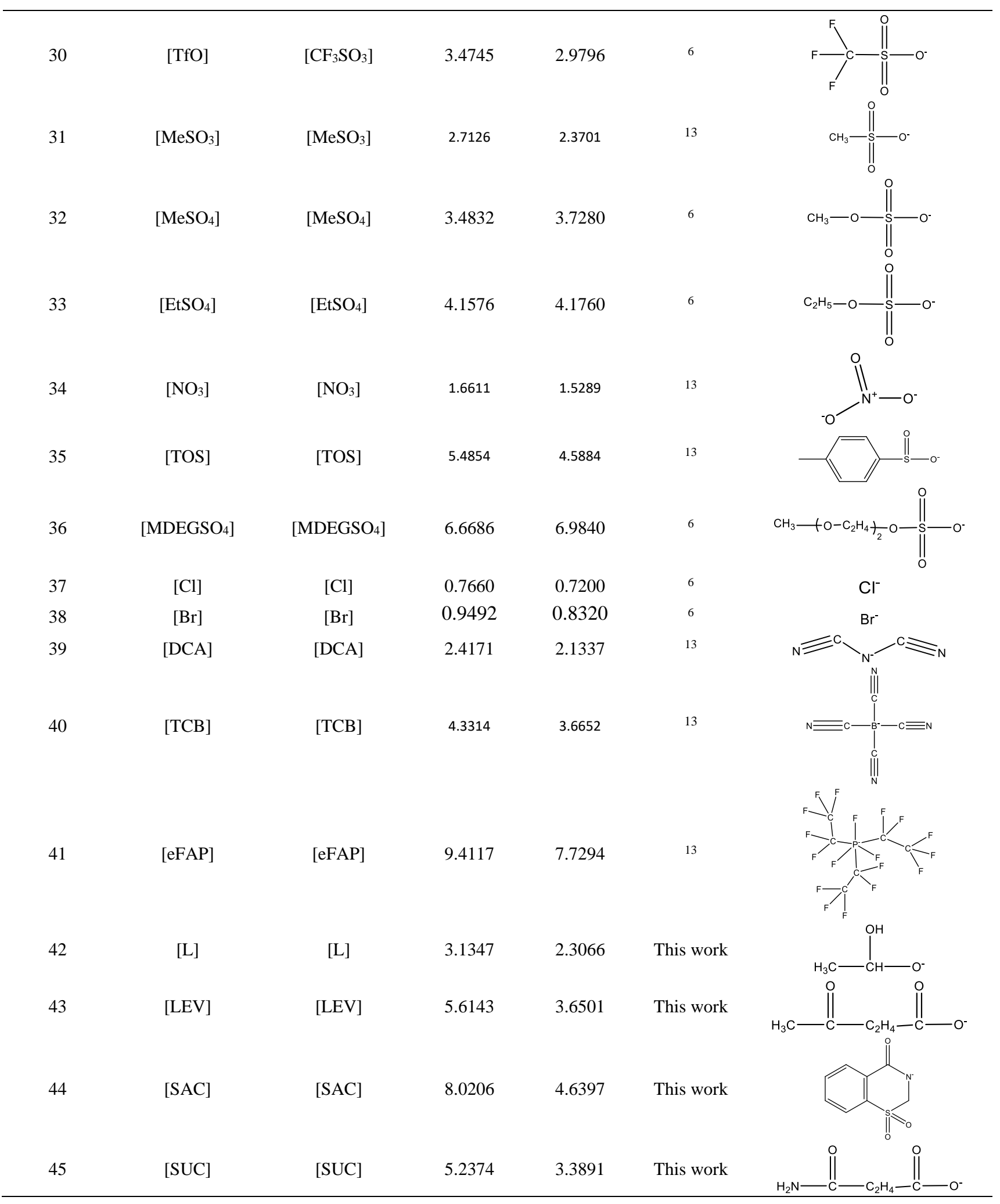


This work
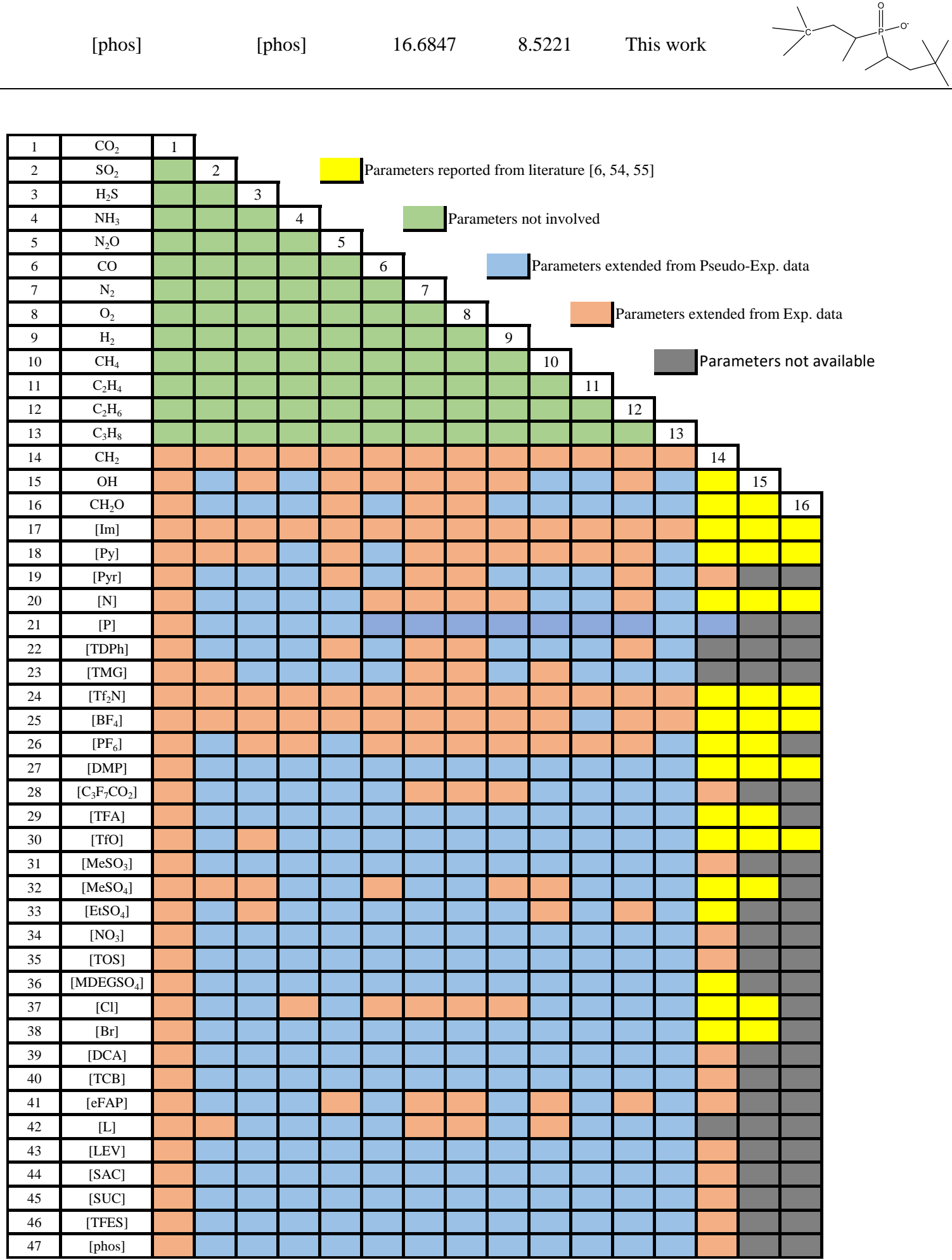

Figure 3. The extended UNIFAC-IL-Gas group interaction parameter matrix. 
Like many other UNIFAC-IL extensions, the interaction parameters between conventional main groups are taken directly from the original UNIFAC parameter matrix. Meanwhile, in order to combine the ILsolute and IL-gas systems in one UNIFAC-IL-Gas model, some interaction parameters between IL and conventional main groups regressed from IL-solute systems by Roughton et al. ${ }^{6}$ have been adopted. That is to say, this model is not limited to IL-solute or IL-gas systems, but can be applied in IL-solutegas systems, which is very important for the study of IL-based mixture solvent application in gas separation processes. In addition, the interaction parameters between IL main groups (i.e. cations and anions) are assumed to be zero considering the strong interaction and weak dissociation of ion pairs. We should note that the interaction parameters between different gases are not involved or considered in the current model extension, as such parameters are typically not available in UNIFAC-tables. Figure 3 presents the group interaction parameter matrix of the extended UNIFAC-IL-Gas model. In this work, we consider in the model extension a total number of 100 ILs (see Appendix) from 6 cation families and 24 anion, and 13 gases including $\mathrm{CO}_{2}{ }^{17,63-114}, \mathrm{SO}_{2}{ }^{115-119}, \mathrm{H}_{2} \mathrm{~S}^{25,90,120-128}, \mathrm{NH}_{3}{ }^{129-131}, \mathrm{~N}_{2} \mathrm{O}^{77,80,132-136}$, $\mathrm{CO}^{64,96,137-140}, \quad \mathrm{~N}_{2}{ }^{64,71,80,96,134,139,141,142}, \quad \mathrm{O}_{2}{ }^{64,71,72,77,96,139,141-144}, \quad \mathrm{H}_{2}{ }^{64,71,75,96,137,139,142,143,145-148}$ $\mathrm{CH}_{4}{ }^{64,76,91,141,142,149-153}, \mathrm{C}_{2} \mathrm{H}_{4}{ }^{76,77,141}, \mathrm{C}_{2} \mathrm{H}_{6}{ }^{64,76,91,101,134,141,154,155}, \mathrm{C}_{3} \mathrm{H}_{8}{ }^{74,110,156}$.

\section{Results and discussion}

\subsection{Experimental data extension}

In this section, 7034 experimental gas solubility data in ILs with a range of temperature, 283.15$384.15 \mathrm{~K}$, and pressure, 0.05-973 bar (see Table S3, S4, S6, in the Supporting Information) are applied for the UNIFAC-IL model extension. As shown in Figure 3, group interaction parameters with orange color in the extended UNIFAC-IL-Gas parameter matrix are regressed from IL-gas systems by minimizing the objective function, i.e. the average absolute relative deviation (AARD) \% between experimental and calculated gas solubility (mole fraction of gas in IL), as shown in Eq. (22).

$$
\text { O.F. }=A A R D(\%)=\frac{1}{N} \sum_{1}^{N}\left|\frac{x_{i}^{e x p}-x_{i}^{c a l}}{x_{i}^{\text {exp }}}\right| \times 100 \%
$$

where $i$ represents the data point and $N$ denotes the total number of the regressed data points. $x_{i}^{c a l}$ and $x_{i}^{\text {exp }}$ are the gas solubility in ILs that can be directly taken from the experimental database and calculated from phase equilibrium equation (see Eq.23), respectively.

$$
x_{\text {gas }}=\frac{y_{\text {gas } P} P\left(T, P, y_{\text {gas }}\right)}{\gamma_{\text {gas }} P_{\text {gas }}^{S}}
$$

In Eq. 23, the activity coefficient of gas $\left(\gamma_{\text {gas }}\right)$ can be calculated from UNIFAC-IL-Gas model and the mole composition of gas in the vapor phase $\left(y_{\text {gas }}\right)$ is assumed to be 1 due to the negligible vapor pressure of ILs. P represents the phase equilibrium pressure of the studied IL-gas system. The fugacity coefficient of gas $\left(\varphi\left(T, P, y_{\text {gas }}\right)\right)$ can be calculated by the Peng-Robinson equation of state, while the saturated vapor pressure of gas $\left(P_{\text {gas }}^{S}\right)$ can be estimated from suitable correlations such as the Wagner, DIPPR, and Antoine equations. In this work, both DIPPR and Antoine equations were considered for different gases.

One of nonlinear programming solvers "lindoglobal" in GAMS (24.4.6) was used to solve this regression problem. Considering the complexity of this problem, the interaction parameters associated 
with the IL-CO2 systems are regressed first, and then the interaction parameters associated with other IL-gas systems are regressed. To evaluate the reliability of the regressed interaction parameters, as well as the predictive performance of the extended UNIFAC-IL-Gas (Exp.) model, nearly $75 \%$ of the involved experimental data points (i.e. training dataset) are used for the regression, while a certain number of remaining data points (i.e. Test dataset1) are used for prediction purposes.

The AARD (\%) between the experimental and calculated $x_{\text {gas }}$ of different gases in ILs range from $12 \%$ for gaseous hydrocarbons $\left(\mathrm{CH}_{4}, \mathrm{C}_{2} \mathrm{H}_{4}, \mathrm{C}_{2} \mathrm{H}_{6}, \mathrm{C}_{3} \mathrm{H}_{8}\right)$ to $22 \%$ for the gas dataset covering $\mathrm{CO}, \mathrm{N}_{2}, \mathrm{O}_{2}, \mathrm{H}_{2}$ in the training dataset. As expected, the AARD $(\%)$ from the test dataset is higher than, but rather close to, its corresponding AARD (\%) from the training dataset. The AARD (\%) between the experimental and calculated $x_{g a s}$ of different gases in ILs for both the training and test datasets can be found in Table 2. To better illustrate the calculation results, comparisons between the experimental and calculated $x_{\text {gas }}$ of all gases in ILs from the training and test datasets are presented in Figures 4 and 5, respectively. The resulting AARD (\%) of prediction for the test dataset shows a reliable predictive ability of the extended UNIFAC-IL-Gas (Exp.) model. The new obtained group interaction parameters with their values are provided in Table S2 (Supporting Information).

Table 2: Summary of the extended UNIFAC-IL-Gases (Exp.) model for both training and test datasets

\begin{tabular}{llllll}
\hline \multirow{2}{*}{ Gas dataset } & Involved gases & \multicolumn{2}{c}{ Training dataset } & \multicolumn{2}{c}{ Test dataset1 } \\
& & Data points & *AARD\% & Data points & ${ }^{*}$ AARD\% \\
\hline 1 & $\mathrm{CO}_{2}$ & 2345 & 14.5 & 1083 & 16.5 \\
2 & $\mathrm{SO}_{2}, \mathrm{H}_{2} \mathrm{~S}, \mathrm{NH}_{3}, \mathrm{~N}_{2} \mathrm{O}$ & 1533 & 12.7 & 395 & 19.2 \\
3 & $\mathrm{CO}, \mathrm{N}_{2}, \mathrm{O}_{2}, \mathrm{H}_{2}$ & 681 & 22.1 & 96 & 35.0 \\
4 & $\mathrm{CH}_{4}, \mathrm{C}_{2} \mathrm{H}_{4}, \mathrm{C}_{2} \mathrm{H}_{6}, \mathrm{C}_{3} \mathrm{H}_{8}$ & 877 & 11.5 & 24 & 14.2 \\
\hline
\end{tabular}

${ }^{*}$ AARD\% of both training and test datasets are calculated from Eq. 22

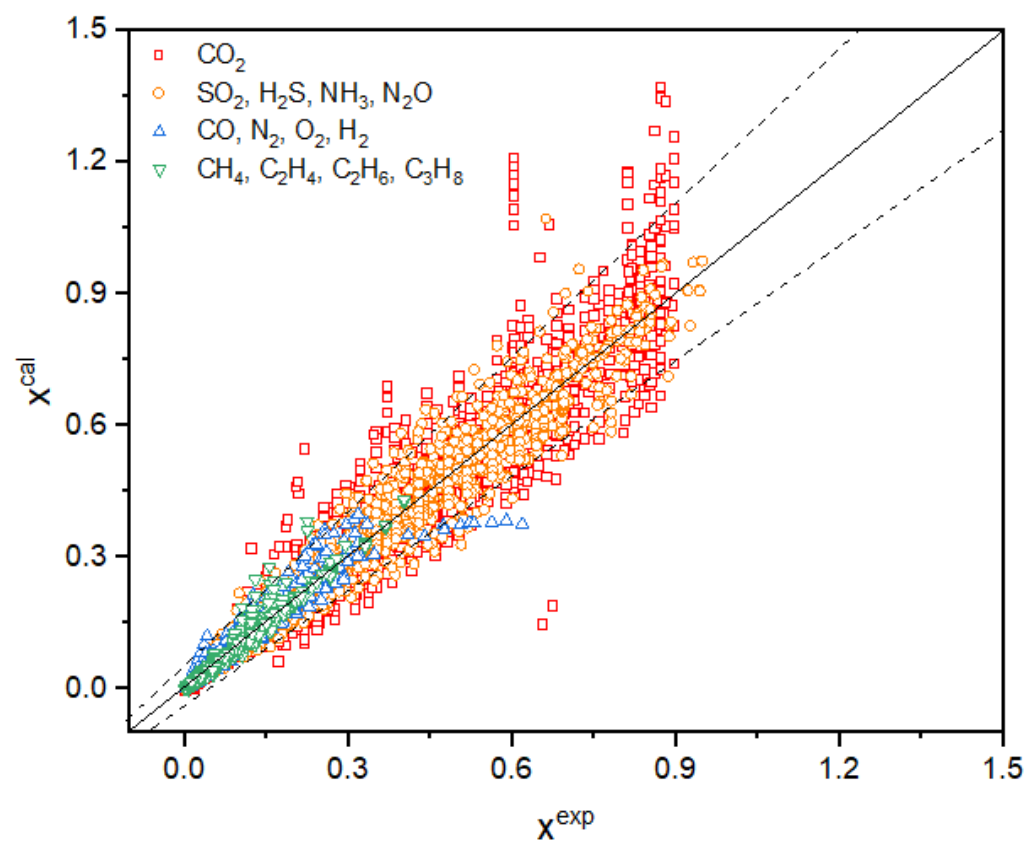

Figure 4. Comparison of experimental and UNIFAC-IL-Gas calculated gas solubilities of different gases in ILs from the training dataset 


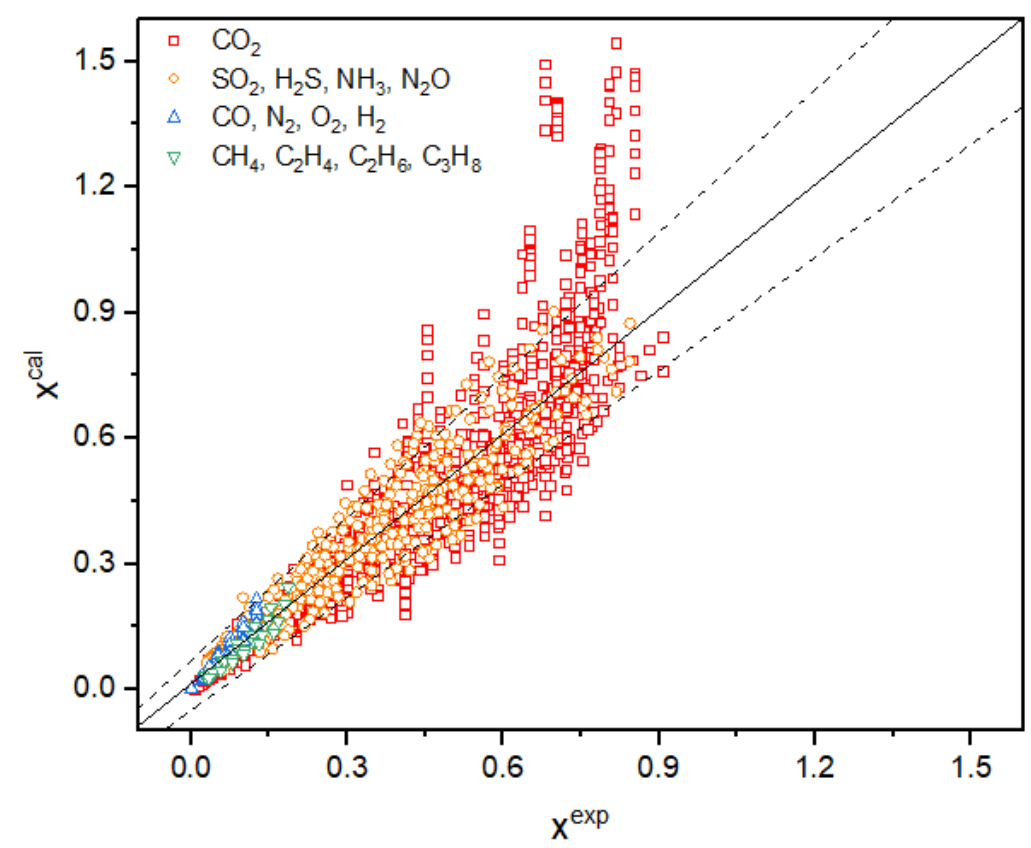

Figure 5. Comparison of experimental and UNIFAC-IL-Gas (Exp.) predicted gas solubilities of different gases in ILs from Test dataset1

\subsection{Pseudo-experimental data extension}

As mentioned above, computational data from the COSMO-RS calculation are very useful because of the insufficient experimental data for some important IL-gas systems. In this work, we only use the COSMO-RS model to generate computational data, but it is not included in the UNIFAC-IL-Gas model extension. Although gas solubility data can be generated directly from COSMO-RS calculations where the saturated vapor pressure is estimated by using the information of gas-phase energy, we use the pseudo-experimental data of infinite dilution activity coefficient since it allows consistent vapor pressure calculations (DIPPR or Antoine method) for both experiment and pseudo-experimental data based regression. To improve the reliability of the computational $\gamma^{\infty}$ from COSMO-RS model, a number of calculated $\gamma^{\infty}$ from validated UNIFAC-IL-Gas (Exp.) were used for calibrations. In this work, a linear calibrated COSMO-RS model involving temperature $(T)$ was employed, as shown in Eq.24. This calibration method for the COSMO-RS model has been used previously and suggested in several published works. ${ }^{18,21,48,49}$ In the last part of this section, the testing results from Test dataset2 also verify the reliability of this calibration.

$$
\gamma^{\infty, p s e u d o}=a \gamma^{\infty, \operatorname{CoSMO}-R S}+b+c T
$$

where $\gamma^{\infty, \text { pasudo }}$ and $\gamma^{\infty, \operatorname{COSMO}-R S}$ are the calibrated $\gamma^{\infty}$ and the $\gamma^{\infty}$ calculated directly from COSMORS, respectively. The adjustable parameters $(a, b$ and $c)$ of this linear calibrated model can be obtained by minimizing:

$$
A A R D(\%)=\frac{1}{N} \sum_{1}^{N}\left|\frac{\gamma_{i}^{\infty, e x p}-\gamma_{i}^{\infty, p s e u d o}}{\gamma_{i}^{\infty, e x p}}\right| \times 100 \%
$$


where $\gamma_{i}^{\infty, \text { pseudo }}$ and $\gamma_{i}^{\infty, e x p}$ are the pseudo-experimental $\gamma^{\infty}$ and experimental $\gamma^{\infty}$ of data point $i$, respectively. $N$ denotes the total number of the regressed data points. In this equation, $\gamma_{i}^{\infty, e x p}$ are calculated from validated UNIFAC-IL-Gas (Exp.) model.

In this section, we will calibrate the computational data generated from COSMO-RS. The purpose of this calibration is to narrow the difference between experimental and computational data. To complement the insufficient amount of experimental data, a total of $6,610 \gamma^{\infty, C O S M O-R S}$ covering various IL-gas systems under different temperatures (see Supporting Information) are computed directly from COSMOthermX software, where the $\sigma$-profiles of the IL functional groups and studied gases are taken from the IL Thermo database. The detailed information of $\gamma^{\infty, p s e u d o}$ and $\gamma^{\infty, C O S M O-R S}$ for each gas is presented in Table 3. From the linear regression results, we can observe that all gases with calibration have lower AARD\% between the COSMO-RS based computational $\gamma^{\infty}$ and UNIFACIL-Gas (Exp.) model based calculated $\gamma^{\infty}$, and only 3 gases (i.e. $\mathrm{O}_{2}, \mathrm{C}_{2} \mathrm{H}_{6}, \mathrm{C}_{3} \mathrm{H}_{8}$ ) have AARD\% higher than 20\%. These linear calibrations for each gas can be validated from the testing results of AARD $\%$ between experimental $x_{g a s}$ and calculated $x_{g a s}$ from calibrated $\gamma^{\infty}$.

Table 3: Calibration of the COSMO-RS model for generating pseudo-experimental data. The calibration parameters refer to Eq. 24.

\begin{tabular}{lcccccc}
\hline Gas & $\begin{array}{l}\text { AARD\% without } \\
\text { calibration }\end{array}$ & $a$ & $b$ & $c$ & \multicolumn{2}{c}{$\begin{array}{l}\text { Calibration parameters } \\
\text { calibration }\end{array}$} \\
\hline $\mathrm{SO}_{2}$ & 4.5 & 1.0000 & -0.0620 & 0.0002 & 4.0 & $\begin{array}{l}\text { Number of data } \\
\text { points } \\
\text { calibration }\end{array}$ \\
$\mathrm{H}_{2} \mathrm{~S}$ & 54.0 & 0.8000 & 0.6850 & -0.0010 & 8.5 & 30 \\
$\mathrm{NH}_{3}$ & 74.5 & 1.6000 & 0.3370 & -0.0001 & 7.2 & 30 \\
$\mathrm{CO}$ & 54.1 & 1.1500 & -0.4710 & 0.0006 & 8.5 & 60 \\
$\mathrm{~N}_{2}$ & 22.2 & 1.5000 & 0.7060 & -0.0030 & 8.8 & 30 \\
$\mathrm{O}_{2}$ & 59.0 & 1.5210 & 2.1930 & -0.0060 & 10.4 & 30 \\
$\mathrm{H}_{2}$ & 57.1 & 2.5820 & 0.1970 & -0.0010 & 22.6 & 90 \\
$\mathrm{~N}_{2} \mathrm{O}$ & 19.5 & 0.8360 & -0.2140 & 0.0006 & 3.8 & 60 \\
$\mathrm{CH}_{4}$ & 35.3 & 0.6620 & -0.1980 & 0.0080 & 16.6 & 60 \\
$\mathrm{C}_{2} \mathrm{H}_{4}$ & 20.3 & 0.6390 & 1.6460 & -0.0030 & 14.7 & 40 \\
$\mathrm{C}_{2} \mathrm{H}_{6}$ & 37.2 & 0.7450 & -1.3690 & 0.0050 & 31.7 & 90 \\
$\mathrm{C}_{3} \mathrm{H}_{8}$ & 44.5 & 0.8000 & -1.1810 & 0.0070 & 36.8 & 40 \\
\hline
\end{tabular}

Based on the pseudo-experimental data from the calibrated COSMO-model, the remaining unknown group interaction parameters (Marked in blue) in the extended UNIFAC-IL-Gas parameter matrix are regressed by minimizing the AARD \% between the experimental and calculated gas solubility, as shown in Eq. (26).

$$
\operatorname{AARD}(\%)=\frac{1}{N} \sum_{1}^{N}\left|\frac{\gamma_{i}^{\infty, p s e u d o}-\gamma_{i}^{\infty, c a l}}{\gamma_{i}^{\infty} \text {,pseudo }}\right| \times 100 \%
$$

where $\gamma_{i}^{\infty, p s e u d o}$ and $\gamma_{i}^{\infty, c a l}$ are the pseudo-experimental and calculated $\gamma^{\infty}$ of data point $i$, respectively. $N$ denotes the total number of the regressed data points. 
Table 4 summarizes the AARD $(\%)$ between $\gamma_{i}^{\infty, p s e u d o}$ and $\gamma_{i}^{\infty, c a l}$ of all pseudo-experimental data points. To evaluate the predictive performance of the obtained UNIFAC-IL-Gas (Pseudo-Exp.) model, a test dataset (i.e. Test dataset2) including 347 experimental data points is applied. The AARD (\%) between the experimental $x_{g a s}$ and $x_{g a s}$ calculated from UNIFAC-IL-Gas (Pseudo-Exp.) model for the test dataset is also provided in Table 2. Compared to the extension of UNIFAC-IL-Gas (Exp.) model, the AARD (\%) from pseudo-experimental data presents similar fitting results, but the predictive reliability of this UNIFAC-IL-Gas (Pseudo-Exp.) model is not as good as its corresponding UNIFACIL-Gas (Exp.) model. Nevertheless, pseudo-experimental data from the calibrated COSMO-RS model is still a good supplementary data source when experimental data are not available. To better illustrate the calculation results, comparisons between $\ln \left(\gamma_{i}^{\infty, p s e u d o}\right)$ and $\ln \left(\gamma_{i}^{\infty, c a l}\right)$ of all pseudo-experimental data points are presented in Figure 6, and comparisons between the experimental and predicted $x_{g a s}$ from UNIFAC-IL-Gas (Pseudo-Exp.) model are given in Figure 7. The resulting AARD (\%) of prediction for the test dataset shows an acceptable predictive performance of the extended UNIFACIL-Gas (Pseudo-Exp.) model. The values of these new group interaction parameters in UNIFAC-ILGas (Pseudo-Exp.) model are listed in Table S2 (Supporting Information).

Table 4: Summary of the extended UNIFAC-IL-Gas (Pseudo-Exp.) model for both training and test datasets

\begin{tabular}{lllclc}
\hline \multirow{2}{*}{ Gas dataset } & \multicolumn{2}{c}{ Training dataset } & \multicolumn{2}{c}{ Test dataset2 } \\
& \multicolumn{1}{c}{ Involved gases } & \multicolumn{2}{c}{ (pseudo-experimental data) } & (experimental data) \\
& & Data points & AARD\% & Data points & AARD\% \\
\hline 2 & $\mathrm{SO}_{2}, \mathrm{H}_{2} \mathrm{~S}, \mathrm{NH}_{3}, \mathrm{~N}_{2} \mathrm{O}$ & 2280 & 8.1 & 169 & 12.5 \\
3 & $\mathrm{CO}, \mathrm{N}_{2}, \mathrm{O}_{2}, \mathrm{H}_{2}$ & 2090 & 9.6 & 88 & 35.1 \\
4 & $\mathrm{CH}_{4}, \mathrm{C}_{2} \mathrm{H}_{4}, \mathrm{C}_{2} \mathrm{H}_{6}, \mathrm{C}_{3} \mathrm{H}_{8}$ & 2240 & 13.5 & 86 & 22.8 \\
\hline
\end{tabular}




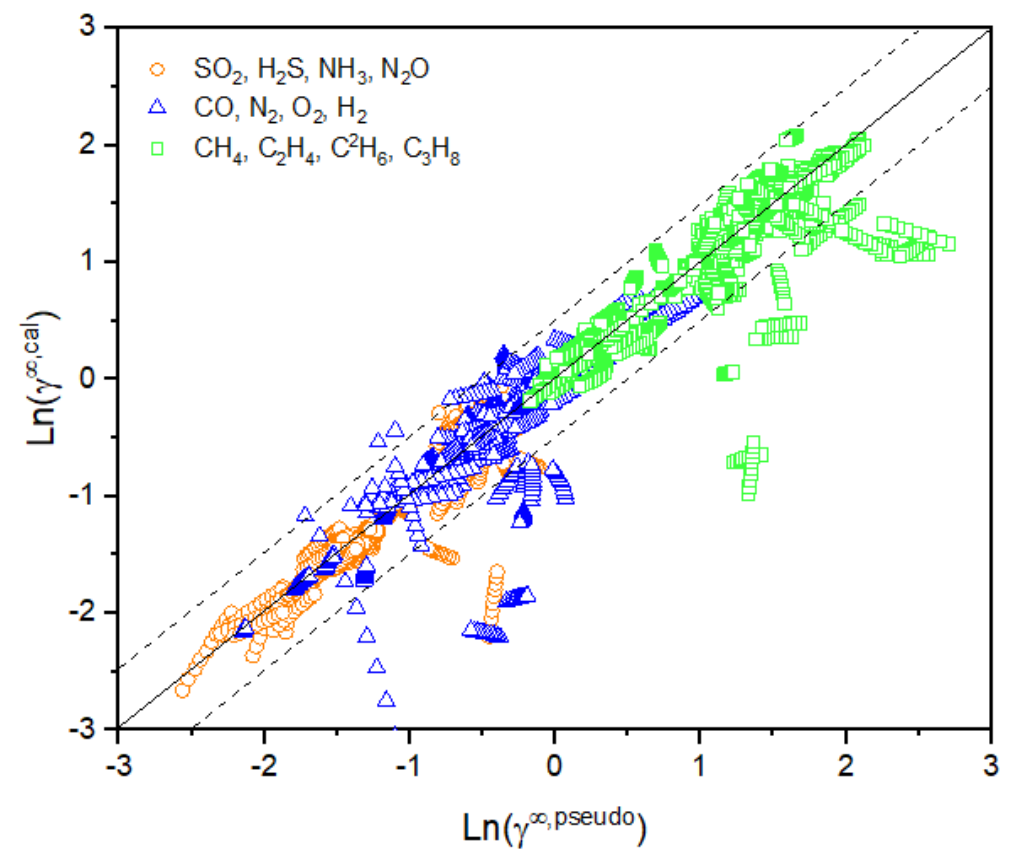

Figure 6. Comparison of the pseudo-experimental and model (UNIFAC-IL-Gas) calculated $\gamma^{\infty}$ for different gases in ILs

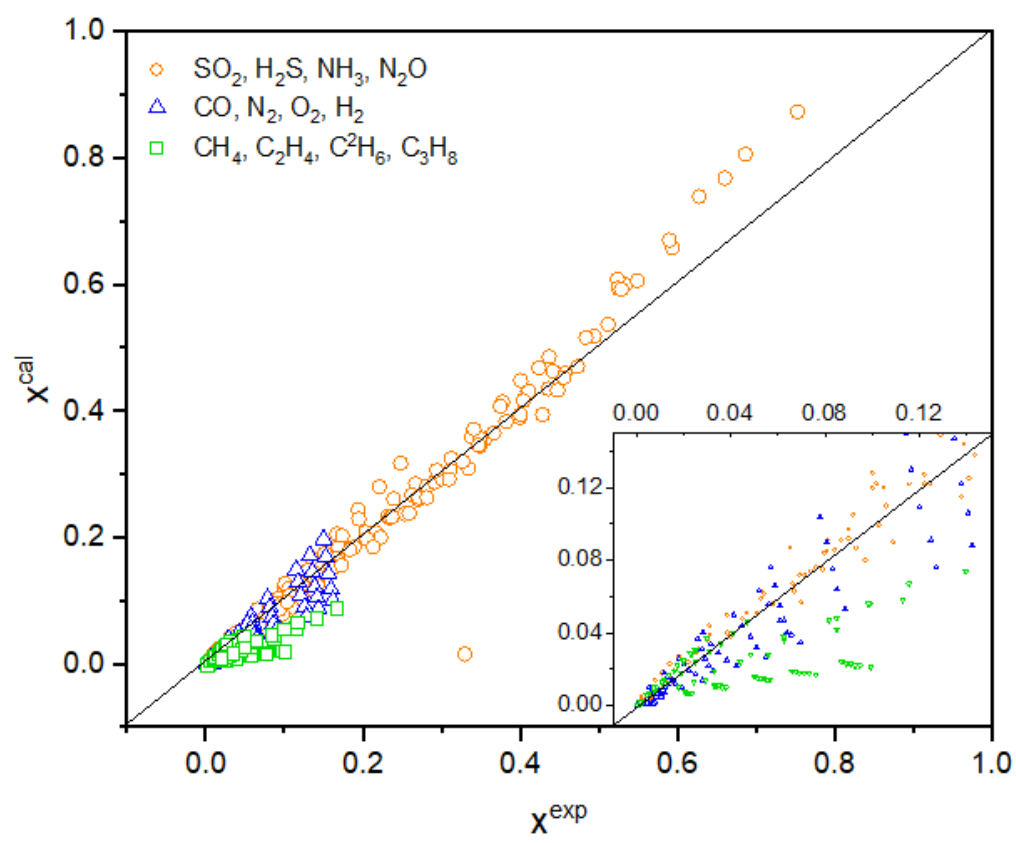

Figure 7. Comparison of the experimental and model (UNIFAC-IL-Gas) predicted gas solubility for different gases in ILs (experimental data are taken from Test dataset2) 


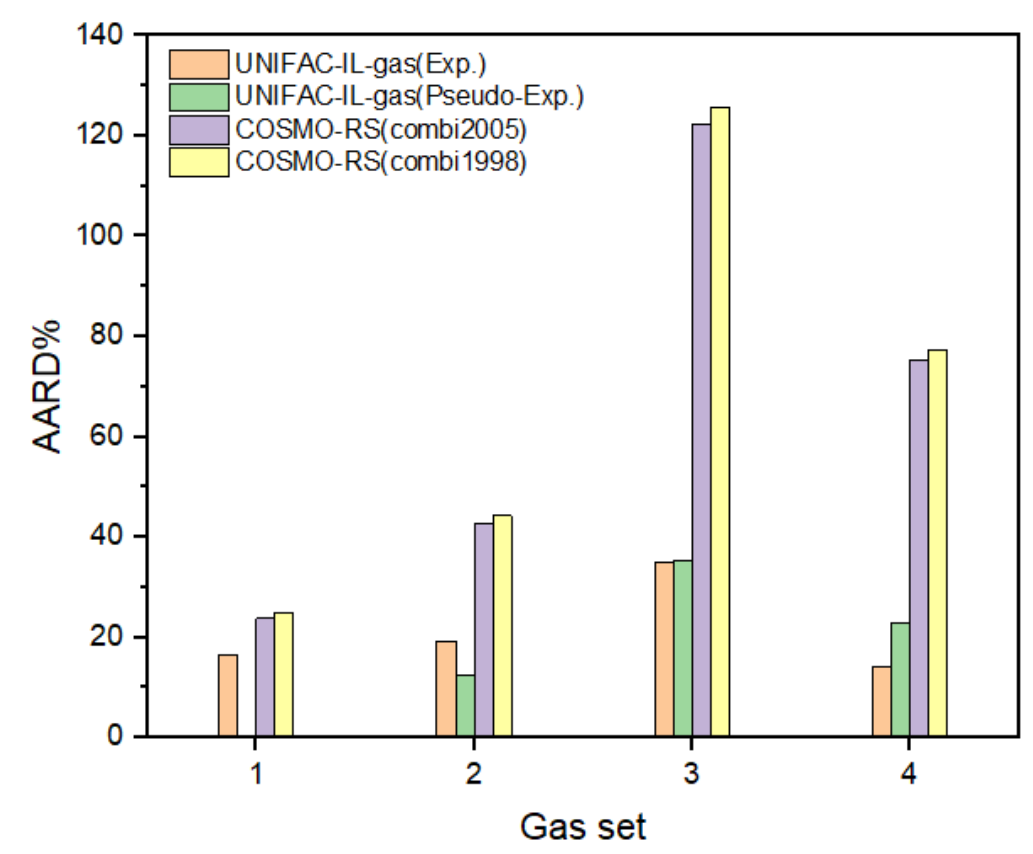

Figure 8: Comparisons between the prediction result (expressed as AARD\%) from the UNIFAC-IL and COSMO-RS based model ${ }^{16}$ for all studied gas datasets. (Gas dataset1: $\mathrm{CO}_{2} ;$ Gas dataset2: $\mathrm{SO}_{2}$, $\mathrm{H}_{2} \mathrm{~S}, \mathrm{NH}_{3}, \mathrm{NO}_{2}$; Gas dataset3: $\mathrm{CO}, \mathrm{N}_{2}, \mathrm{O}_{2}, \mathrm{H}_{2}$; Gas dataset4: $\mathrm{CH}_{4}, \mathrm{C}_{2} \mathrm{H}_{4}, \mathrm{C}_{2} \mathrm{H}_{6}, \mathrm{C}_{3} \mathrm{H}_{8}$ )

Among all studied IL-gas systems, gases $\left(\mathrm{CO}, \mathrm{N}_{2}, \mathrm{O}_{2}, \mathrm{H}_{2}\right)$ involved in the Gas dataset 3 have relatively large deviation (about 30\%) for both UNIFAC-IL-Gas (Exp.) and UNIFAC-IL-Gas (Pseudo-Exp.) models, as shown in Tables 2 and 4. This can be explained by the fact that these gases have lower vapor pressures compared with other studied gases, which usually leads to lower solubility in ILs, so their experimental data itself have higher deviation. Nevertheless, the extended UNIFAC model has much better predictive performance for $\mathrm{CO}, \mathrm{N} 2, \mathrm{O} 2$ and $\mathrm{H} 2$ than COSMO-RS, for which AARD is over $100 \%$ (see Figure 8). In addition, it is found that there is no significant difference in the deviation of IL systems with different cation or anion families. However, a small number of data points for some IL-CO systems show very large deviations, as shown in Figures 2 and 3. This can be explained as follows: (1) the system pressure of some data points for $\mathrm{CO}_{2}-\mathrm{IL}$ systems (e.g. 1-hexyl-3-methylimidazolium saccharinate and 1-hexyl-3-methylimidazolium tris(pentafluoroethyl)trifluorophosphate) is very low or very high; (2) the number of data points for some $\mathrm{CO}_{2}$-IL systems (e.g. trihexyl tetradecyl phosphonium bis(2,4,4-trime-thylpentyl)phosphinate, 1-butyl-3-methylimidazolium 2-(2methoxyethoxy)ethylsulfate) is very small; (3) the experimental data of some $\mathrm{CO}_{2}$-IL systems (mainly imidazolium dicyanamide) from different data sources have some deviations.

It is worth mentioning that the DIPPR and Antoine equations present different regression results for many IL-gas systems, especially for the gases with very low critical temperature. This can be explained by the fact that both the DIPPR and Antoine equations are sufficient for estimating the vapor pressure below the critical temperature and they provide similar vapor pressure values in the range of certain temperatures (e.g. CO 68.15-132.92 K). However, hypothetical vapor pressure extrapolated from these equations cannot express some gas systems well at temperatures above the critical temperature. In fact, 
from a thermodynamic point of view, when the system temperature is higher than the critical temperature of the component, the liquid vapor pressure of the component no longer exists, and so, the vapor pressure (above the critical temperature) calculated from the DIPPR or Antoine equation is regarded as a pseudo-vapor pressure. In this work, the temperature of most studied IL-gas systems is much higher than the critical temperature of those involved gases and different vapor pressure equations present different regression results. This is one of the reasons why the AARD\% of IL-gas systems is generally higher than for other IL-solutes systems. For this reason, we use either DIPPR or Antoine equation for different IL-gas systems based on their regression performance. It should be noted that when using this UNIFAC-IL-Gas model, the vapor pressure equation (DIPPR or Antoine) and coefficients must be consistent with the equation and coefficients used for each gas in this work. The details of the vapor calculation method and their corresponding equation parameters for all involved gases are provided in Table S8 (Supporting Information).

On the other hand, although the computational data generated from COSMO-RS have errors of its own, a calibration method is used to calibrate these computational data for reducing the impact of such inherent errors. Most importantly, the UNIFAC-IL-Gas (Pseudo-Exp.) model extended from these calibrated computational data (i.e. pseudo-experimental data) is verified by Test dataset 2 containing $100 \%$ experimental data. In order to compare the prediction performance of the extended UNIFAC-ILGas models with COSMO-RS models, the prediction results of AARD\% from the UNIFAC-IL and COSMO-RS based models for 4 gas datasets covering all studied gases are plotted in Figure 8 . The prediction results from different versions (combi2005 and combi1998) of the COSMO-RS model are taken from Lei's work. ${ }^{16}$ Clearly, both UNIFAC-IL-Gas (Exp.) and UNIFAC-IL-Gas (Pseudo-Exp.) models have much better predictive performance than the COSMO-RS models, especially for the gases included in Gas dataset 3 and dataset4. These comparisons highlight the reliability and applicability of the extended UNIFAC-IL-Gas model developed in this work. This model can be easily used for screening suitable ILs for many gas separations such as natural gas upgrading and $\mathrm{NH}_{3}$ recovery prior to their corresponding experimental work.

\section{Conclusions}

A comprehensive database of IL gas-systems including experimental data from published works and pseudo-experimental data from calibrated COSMO-RS model have been developed. By using a hierarchical extension strategy, the UNIFAC-IL was extended to various IL-systems from a large number of experimental and pseudo-experimental data, and then a combined UNIFAC-IL-Gas model consisting of UNIFAC-IL-Gas (Exp.) and UNIFAC-IL-Gas (Pseudo-Exp.) was obtained. We should note that COSMO-RS model is only used to obtain pseudo-experimental data, and it is not involved in the UNIFAC-IL-Gas model extension. Overall, 13 gases, 3 conventional functional groups, 7 cation skeleton groups, and 24 anion groups are considered in this extended model. The calculation results of both training and test datasets, presented as comparisons between the experimental/pseudoexperimental and calculated gas solubility from the UNIFAC-IL-Gas model, show the reliable predictive performance of the UNIFAC-IL-Gas model obtained in this work.

This UNIFAC-IL-Gas model can be applied in solvent screening, process optimization and evaluation in the design stage of gas separation processes involving ILs. Moreover, this model can also be used for IL-based mixture solvents design since it combines IL-gas and other IL-solute systems, giving significant opportunity to potentially expand the application of ILs in gas separation processes. Furthermore, the current UNIFAC-IL-Gas model can be updated, or further extended, to new gas-IL systems that are currently not included in this study, once their experimental data becomes available.

\section{Acknowledgements}

This research work was financially supported by the China Scholarship Council (No. 201708440264) and the Technical University of Denmark. 


\section{Supporting Information}

Tables S1-S8 summarize all the information used in the extension of the UNIFAC-IL-Gas model. This information is available free of charge via the Internet at http://pubs.acs.org/.

\section{References}

(1) Rogers, R. D.; Seddon, K. R.: Ionic liquids--solvents of the future? Science 2003, 302, 792-793.

(2) Zeng, S.; Zhang, X.; Bai, L.; Zhang, X.; Wang, H.; Wang, J.; Bao, D.; Li, M.; Liu, X.; Zhang, S.: Ionic-liquid-based CO2 capture systems: structure, interaction and process. Chemical reviews 2017, 117, 9625-9673.

(3) Liu, X.; Chen, Y.; Zeng, S.; Zhang, X.; Zhang, S.; Liang, X.; Gani, R.; Kontogeorgis, G. M.: Structure optimization of tailored ionic liquids and process simulation for shale gas separation. AIChE Journal 2020, 66, e16794.

(4) Chen, Y.; Liu, X.; Kontogeorgis, G. M.; Woodley, J. M.: Ionic-Liquid-Based Bioisoprene Recovery Process Design. Industrial \& Engineering Chemistry Research 2020, 59, 7355-7366.

(5) Song, Z.; Li, X.; Chao, H.; Mo, F.; Zhou, T.; Cheng, H.; Chen, L.; Qi, Z.: Computer-aided ionic liquid design for alkane/cycloalkane extractive distillation process. Green Energy \& Environment 2019, 4, 154-165.

(6) Roughton, B. C.; Christian, B.; White, J.; Camarda, K. V.; Gani, R.: Simultaneous design of ionic liquid entrainers and energy efficient azeotropic separation processes. Computers \& Chemical Engineering 2012, 42, 248-262.

(7) Lei, Z.; Dai, C.; Zhu, J.; Chen, B.: Extractive distillation with ionic liquids: a review. AIChE Journal 2014, 60, 3312-3329.

(8) Chen, Y.; Gani, R.; Kontogeorgis, G. M.; Woodley, J. M.: Integrated ionic liquid and process design involving azeotropic separation processes. Chemical Engineering Science 2019, 203, 402-414.

(9) Jongmans, M. T.; Schuur, B.; de Haan, A. B.: Ionic liquid screening for ethylbenzene/styrene separation by extractive distillation. Industrial \& engineering chemistry research 2011, 50, 10800-10810.

(10) Zhu, Z.; Ri, Y.; Jia, H.; Li, X.; Wang, Y.; Wang, Y.: Process evaluation on the separation of ethyl acetate and ethanol using extractive distillation with ionic liquid. Separation and Purification Technology 2017, 181, 44-52.

(11) Pereiro, A. B.; Rodríguez, A.: An ionic liquid proposed as solvent in aromatic hydrocarbon separation by liquid extraction. AIChE journal 2010, 56, 381-386.

(12) Ventura, S. P.; e Silva, F. A.; Quental, M. V.; Mondal, D.; Freire, M. G.; Coutinho, J. A.: Ionic-liquid-mediated extraction and separation processes for bioactive compounds: past, present, and future trends. Chemical reviews 2017, 117, 6984-7052.

(13) Song, Z.; Zhang, C.; Qi, Z.; Zhou, T.; Sundmacher, K.: Computer - aided design of ionic liquids as solvents for extractive desulfurization. AIChE Journal 2018, 64, 1013-1025.

(14) Chen, Y.; Koumaditi, E.; Gani, R.; Kontogeorgis, G. M.; Woodley, J. M.: Computer-Aided Design of Ionic Liquids for Hybrid Process Schemes. Computers \& Chemical Engineering 2019, 106556. 
(15) Song, Z.; Zhang, C.; Qi, Z.; Zhou, T.; Sundmacher, K.: Computer - aided design of ionic liquids as solvents for extractive desulfurization. AIChE Journal 2018, 64, 1013-1025.

(16) Lei, Z.; Dai, C.; Chen, B.: Gas solubility in ionic liquids. Chemical reviews 2014, 114, 1289-1326.

(17) Zhang, X.; Liu, Z.; Wang, W.: Screening of ionic liquids to capture CO2 by COSMO - RS and experiments. AIChE journal 2008, 54, 2717-2728.

(18) Zhao, X.; Yang, Q.; Xu, D.; Bao, Z.; Zhang, Y.; Su, B.; Ren, Q.; Xing, H.: Design and screening of ionic liquids for $\mathrm{C} 2 \mathrm{H} 2 / \mathrm{C} 2 \mathrm{H} 4$ separation by COSMO - RS and experiments. AIChE Journal 2015, 61, 2016-2027.

(19) Bedia, J.; Ruiz, E.; de Riva, J.; Ferro, V. R.; Palomar, J.; Rodriguez, J. J.: Optimized ionic liquids for toluene absorption. AIChE Journal 2013, 59, 1648-1656.

(20) Taheri, M.; Dai, C.; Lei, Z.: CO2 capture by methanol, ionic liquid, and their binary mixtures: Experiments, modeling, and process simulation. AIChE Journal 2018, 64, 2168-2180.

(21) Zhao, Y.; Gani, R.; Afzal, R. M.; Zhang, X.; Zhang, S.: Ionic liquids for absorption and separation of gases: An extensive database and a systematic screening method. AIChE Journal 2017, 63, 1353-1367.

(22) Suojiang, Z.; Gani, R.: Ionic Liquids for Absorption and Separation of Gases: An Extensive Database and a Systematic Screening Method. In 2017 AIChE Annual Meeting; AIChE, 2017.

(23) Zeng, S.; Wang, J.; Bai, L.; Wang, B.; Gao, H.; Shang, D.; Zhang, X.; Zhang, S.: Highly selective capture of $\mathrm{CO} 2$ by ether-functionalized pyridinium ionic liquids with low viscosity. Energy \& Fuels 2015, 29, 6039-6048.

(24) Shiflett, M. B.; Yokozeki, A.: Separation of $\mathrm{CO} 2$ and $\mathrm{H} 2 \mathrm{~S}$ using roomtemperature ionic liquid [bmim][PF6]. Fluid Phase Equilibria 2010, 294, 105-113.

(25) Shiflett, M. B.; Niehaus, A. M. S.; Yokozeki, A.: Separation of CO2 and H2S using room-temperature ionic liquid [bmim][MeSO4]. Journal of Chemical \& Engineering Data 2010, 55, 4785-4793.

(26) Handy, H.; Santoso, A.; Widodo, A.; Palgunadi, J.; Soerawidjaja, T. H.; Indarto, A.: H2S-CO2 separation using room temperature ionic liquid [BMIM][Br]. Separation Science and Technology 2014, 49, 2079-2084.

(27) Simoni, L. D.; Lin, Y.; Brennecke, J. F.; Stadtherr, M. A.: Modeling liquidliquid equilibrium of ionic liquid systems with NRTL, electrolyte-NRTL, and UNIQUAC. Industrial \& engineering chemistry research 2008, 47, 256-272.

(28) Lei, Z.; Zhang, J.; Li, Q.; Chen, B.: UNIFAC model for ionic liquids. Industrial \& Engineering Chemistry Research 2009, 48, 2697-2704.

(29) Kato, R.; Gmehling, J.: Systems with ionic liquids: Measurement of VLE and $\gamma \infty$ data and prediction of their thermodynamic behavior using original UNIFAC, mod. UNIFAC (Do) and COSMO-RS (Ol). The Journal of Chemical Thermodynamics 2005, 37, 603-619.

(30) Lei, Z.; Dai, C.; Wang, W.; Chen, B.: UNIFAC model for ionic liquid - CO2 systems. AIChE Journal 2014, 60, 716-729.

(31) Haghtalab, A.; Paraj, A.: Computation of liquid-liquid equilibrium of organic-ionic liquid systems using NRTL, UNIQUAC and NRTL-NRF models. Journal of Molecular Liquids 2012, 171, 43-49.

(32) Nebig, S.; Gmehling, J.: Prediction of phase equilibria and excess properties for systems with ionic liquids using modified UNIFAC: Typical results and present status of the modified UNIFAC matrix for ionic liquids. Fluid phase equilibria 2011, 302, 220-225.

(33) Hector, T.; Gmehling, J.: Present status of the modified UNIFAC model for the prediction of phase equilibria and excess enthalpies for systems with ionic liquids. Fluid Phase Equilibria 2014, 371, 82-92. 
(34) Lei, Z.; Dai, C.; Liu, X.; Xiao, L.; Chen, B.: Extension of the UNIFAC model for ionic liquids. Industrial \& Engineering Chemistry Research 2012, 51, 12135-12144.

(35) Lei, Z.; Dai, C.; Yang, Q.; Zhu, J.; Chen, B.: UNIFAC model for ionic liquid - $\mathrm{CO}(\mathrm{H} 2)$ systems: an experimental and modeling study on gas solubility. AIChE Journal 2014, 60, 4222-4231.

(36) Pereda, S.; Raeissi, S.; Andreatta, A. E.; Bottini, S. B.; Kroon, M.; Peters, C. J.: Modeling gas solubilities in imidazolium based ionic liquids with the [Tf2N] anion using the GC-EoS. Fluid Phase Equilibria 2016, 409, 408-416.

(37) Chen, Y.; Mutelet, F.; Jaubert, J.-N. 1.: Modeling the solubility of carbon dioxide in imidazolium-based ionic liquids with the PC-SAFT equation of state. The Journal of Physical Chemistry B 2012, 116, 14375-14388.

(38) Navarro, P.; Ayuso, M.; Palma, A. M.; Larriba, M.; Delgado-Mellado, N.; García, J. n.; Rodríguez, F.; Coutinho, J. o. A.; Carvalho, P. J.: Toluene/n-heptane separation by extractive distillation with tricyanomethanide-based ionic liquids: experimental and CPA EoS modeling. Industrial \& Engineering Chemistry Research 2018, 57, 14242-14253.

(39) Diedenhofen, M.; Eckert, F.; Klamt, A.: Prediction of infinite dilution activity coefficients of organic compounds in ionic liquids using COSMO-RS. Journal of Chemical \& Engineering Data 2003, 48, 475-479.

(40) Gutiérrez, J. P.; Meindersma, G. W.; de Haan, A. B.: COSMO-RS-based ionic-liquid selection for extractive distillation processes. Industrial \& Engineering Chemistry Research 2012, 51, 11518-11529.

(41) Fang, J.; Zhao, R.; Su, W.; Li, C.; Liu, J.; Li, B.: A molecular design method based on the COSMO - SAC model for solvent selection in ionic liquid extractive distillation. AIChE Journal 2016, 62, 2853-2869.

(42) Dong, Y.; Huang, S.; Guo, Y.; Lei, Z.: COSMO - UNIFAC model for ionic liquids. AIChE Journal 2020, 66, e16787.

(43) Zhu, R.; Taheri, M.; Zhang, J.; Lei, Z.: Extension of the COSMO-UNIFAC Thermodynamic Model. Industrial \& Engineering Chemistry Research 2020, 59, 1693-1701.

(44) Klamt, A.; Eckert, F.: COSMO-RS: a novel and efficient method for the a priori prediction of thermophysical data of liquids. Fluid Phase Equilibria 2000, 172, 43-72.

(45) Banerjee, T.; Singh, M. K.; Khanna, A.: Prediction of binary VLE for imidazolium based ionic liquid systems using COSMO-RS. Industrial \& engineering chemistry research 2006, 45, 3207-3219.

(46) Zhou, T.; Chen, L.; Ye, Y.; Chen, L.; Qi, Z.; Freund, H. r.; Sundmacher, K.: An overview of mutual solubility of ionic liquids and water predicted by COSMO-RS. Industrial \& engineering chemistry research 2012, 51, 6256-6264.

(47) Manan, N. A.; Hardacre, C.; Jacquemin, J.; Rooney, D. W.; Youngs, T. G.: Evaluation of gas solubility prediction in ionic liquids using COSMOthermX. Journal of Chemical \& Engineering Data 2009, 54, 2005-2022.

(48) Farahipour, R.; Mehrkesh, A.; Karunanithi, A. T.: A systematic screening methodology towards exploration of ionic liquids for $\mathrm{CO} 2$ capture processes. Chemical Engineering Science 2016, 145, 126-132.

(49) Liu, X.; Zhou, T.; Zhang, X.; Zhang, S.; Liang, X.; Gani, R.; Kontogeorgis, G. M.: Application of COSMO-RS and UNIFAC for ionic liquids based gas separation. Chemical Engineering Science 2018, 192, 816-828. 
(50) Song, Z.; Zhou, T.; Qi, Z.; Sundmacher, K.: Extending the UNIFAC model for ionic liquid-solute systems by combining experimental and computational databases. AIChE Journal 2020, 66, e16821.

(51) Brignole, E. A.; Bottini, S.; Gani, R.: A strategy for the design and selection of solvents for separation processes. Fluid Phase Equilibria 1986, 29, 125-132.

(52) Karunanithi, A.; Mehrkesh, A.: Computer-Aided Design of Tailor-Made Ionic Liquids, 2013; Vol. 59.

(53) Nebig, S.; Gmehling, J.: Measurements of different thermodynamic properties of systems containing ionic liquids and correlation of these properties using modified UNIFAC (Dortmund). Fluid Phase Equilibria 2010, 294, 206-212.

(54) Dai, C.; Lei, Z.; Chen, B.: Predictive thermodynamic models for ionic liquidSO2 systems. Industrial \& Engineering Chemistry Research 2015, 54, 10910-10917.

(55) Yu, G.; Dai, C.; Lei, Z.: Modified UNIFAC-Lei Model for Ionic Liquid-CH4 Systems. Industrial \& Engineering Chemistry Research 2018, 57, 7064-7076.

(56) Fredenslund, A.; Jones, R. L.; Prausnitz, J. M.: Group - contribution estimation of activity coefficients in nonideal liquid mixtures. AIChE Journal 1975, 21, 10861099.

(57) Constantinescu, D.; Gmehling, J. r.: Further development of modified UNIFAC (Dortmund): revision and extension 6. Journal of Chemical \& Engineering Data 2016, 61, 2738-2748.

(58) Weidlich, U.; Gmehling, J.: A modified UNIFAC model. 1. Prediction of VLE, hE, and. gamma.. infin. Industrial \& engineering chemistry research 1987, 26, 1372 1381.

(59) Hansen, H. K.; Rasmussen, P.; Fredenslund, A.; Schiller, M.; Gmehling, J.: Vapor-liquid equilibria by UNIFAC group contribution. 5. Revision and extension. Industrial \& Engineering Chemistry Research 1991, 30, 2352-2355.

(60) Wittig, R.; Lohmann, J.; Gmehling, J.: Vapor- liquid equilibria by UNIFAC group contribution. 6 . Revision and extension. Industrial \& engineering chemistry research 2003, 42, 183-188.

(61) Nocon, G.; Weidlich, U.; Gmehling, J.; Onken, U.: Prediction of Gas Solubilities by a Modified UNIFAC - Equation. Berichte der Bunsengesellschaft für physikalische Chemie 1983, 87, 17-23.

(62) Dahl, S.; Fredenslund, A.; Rasmussen, P.: The MHV2 model: a UNIFACbased equation of state model for prediction of gas solubility and vapor-liquid equilibria at low and high pressures. Industrial \& engineering chemistry research 1991, 30, 1936-1945.

(63) Shiflett, M. B.; Yokozeki, A.: Solubilities and diffusivities of carbon dioxide in ionic liquids:[bmim][PF6] and [bmim][BF4]. Industrial \& Engineering Chemistry Research 2005, 44, 4453-4464.

(64) Jacquemin, J.; Gomes, M. F. C.; Husson, P.; Majer, V.: Solubility of carbon dioxide, ethane, methane, oxygen, nitrogen, hydrogen, argon, and carbon monoxide in 1butyl-3-methylimidazolium tetrafluoroborate between temperatures $283 \mathrm{~K}$ and $343 \mathrm{~K}$ and at pressures close to atmospheric. The Journal of Chemical Thermodynamics 2006, 38, 490-502.

(65) Chen, Y.; Zhang, S.; Yuan, X.; Zhang, Y.; Zhang, X.; Dai, W.; Mori, R.: Solubility of $\mathrm{CO} 2$ in imidazolium-based tetrafluoroborate ionic liquids. Thermochimica Acta 2006, 441, 42-44.

(66) Yokozeki, A.; Shiflett, M. B.; Junk, C. P.; Grieco, L. M.; Foo, T.: Physical and chemical absorptions of carbon dioxide in room-temperature ionic liquids. The Journal of Physical Chemistry B 2008, 112, 16654-16663.

(67) Revelli, A.-L.; Mutelet, F.; Jaubert, J.-N.: High carbon dioxide solubilities in imidazolium-based ionic liquids and in poly (ethylene glycol) dimethyl ether. The Journal of Physical Chemistry B 2010, 114, 12908-12913. 
(68) Tian, S.; Hou, Y.; Wu, W.; Ren, S.; Pang, K.: Physical properties of 1-butyl3-methylimidazolium tetrafluoroborate/ $\mathrm{N}$-methyl-2-pyrrolidone mixtures and the solubility of $\mathrm{CO} 2$ in the system at elevated pressures. Journal of Chemical \& Engineering Data 2012, 57, $756-763$.

(69) Lei, Z.; Han, J.; Zhang, B.; Li, Q.; Zhu, J.; Chen, B.: Solubility of CO2 in binary mixtures of room-temperature ionic liquids at high pressures. Journal of Chemical \& Engineering Data 2012, 57, 2153-2159.

(70) Lei, Z.; Qi, X.; Zhu, J.; Li, Q.; Chen, B.: Solubility of CO2 in acetone, 1butyl-3-methylimidazolium tetrafluoroborate, and their mixtures. Journal of Chemical \& Engineering Data 2012, 57, 3458-3466.

(71) Zhou, L.; Fan, J.; Shang, X.; Wang, J.: Solubilities of CO2, H2, N2 and O2 in ionic liquid 1-n-butyl-3-methylimidazolium heptafluorobutyrate. The Journal of Chemical Thermodynamics 2013, 59, 28-34.

(72) Afzal, W.; Liu, X.; Prausnitz, J. M.: Solubilities of some gases in four immidazolium-based ionic liquids. The Journal of Chemical Thermodynamics 2013, 63, 8894.

(73) Aki, S. N.; Mellein, B. R.; Saurer, E. M.; Brennecke, J. F.: High-pressure phase behavior of carbon dioxide with imidazolium-based ionic liquids. The Journal of Physical Chemistry B 2004, 108, 20355-20365.

(74) Lee, B.-C.; Outcalt, S. L.: Solubilities of gases in the ionic liquid 1-n-butyl3-methylimidazolium bis (trifluoromethylsulfonyl) imide. Journal of Chemical \& Engineering Data 2006, 51, 892-897.

(75) Jacquemin, J.; Husson, P.; Majer, V.; Gomes, M. F. C.: Influence of the cation on the solubility of $\mathrm{CO} 2$ and $\mathrm{H} 2$ in ionic liquids based on the bis (trifluoromethylsulfonyl) imide anion. Journal of solution chemistry 2007, 36, 967-979.

(76) Anthony, J. L.; Maginn, E. J.; Brennecke, J. F.: Solubilities and thermodynamic properties of gases in the ionic liquid 1-n-butyl-3-methylimidazolium hexafluorophosphate. The Journal of Physical Chemistry B 2002, 106, 7315-7320.

(77) Anthony, J. L.; Anderson, J. L.; Maginn, E. J.; Brennecke, J. F.: Anion effects on gas solubility in ionic liquids. The Journal of Physical Chemistry B 2005, 109, 6366-6374.

(78) Zhang, S.; Yuan, X.; Chen, Y.; Zhang, X.: Solubilities of CO2 in 1-butyl-3methylimidazolium hexafluorophosphate and 1, 1, 3, 3-tetramethylguanidium lactate at elevated pressures. Journal of Chemical \& Engineering Data 2005, 50, 1582-1585.

(79) Kim, Y.; Choi, W.; Jang, J.; Yoo, K.-P.; Lee, C.: Solubility measurement and prediction of carbon dioxide in ionic liquids. Fluid Phase Equilibria 2005, 228, 439-445.

(80) Almantariotis, D.; Stevanovic, S.; Fandino, O.; Pensado, A.; Padua, A. A.; Coxam, J.-Y.; Costa Gomes, M.: Absorption of carbon dioxide, nitrous oxide, ethane and nitrogen by 1-alkyl-3-methylimidazolium $(\mathrm{C} \mathrm{n}$ mim, $\mathrm{n}=2,4,6)$ tris (pentafluoroethyl) trifluorophosphate ionic liquids (eFAP). The Journal of Physical Chemistry B 2012, 116, 7728-7738.

(81) Althuluth, M.; Mota-Martinez, M. T.; Kroon, M. C.; Peters, C. J.: Solubility of carbon dioxide in the ionic liquid 1-ethyl-3-methylimidazolium tris (pentafluoroethyl) trifluorophosphate. Journal of Chemical \& Engineering Data 2012, 57, 3422-3425.

(82) Muldoon, M. J.; Aki, S. N.; Anderson, J. L.; Dixon, J. K.; Brennecke, J. F.: Improving carbon dioxide solubility in ionic liquids. The Journal of Physical Chemistry B 2007, 111, 9001-9009. 
(83) Shin, E.-K.; Lee, B.-C.: High-pressure phase behavior of carbon dioxide with ionic liquids: 1-alkyl-3-methylimidazolium trifluoromethanesulfonate. Journal of Chemical \& Engineering Data 2008, 53, 2728-2734.

(84) Soriano, A. N.; Doma Jr, B. T.; Li, M.-H.: Carbon dioxide solubility in some ionic liquids at moderate pressures. Journal of the Taiwan Institute of Chemical Engineers 2009, 40, 387-393.

(85) Soriano, A. N.; Doma Jr, B. T.; Li, M.-H.: Carbon dioxide solubility in 1ethyl-3-methylimidazolium trifluoromethanesulfonate. The Journal of Chemical Thermodynamics 2009, 41, 525-529.

(86) Shiflett, M. B.; Yokozeki, A.: Phase behavior of carbon dioxide in ionic liquids:[emim][acetate],[emim][trifluoroacetate], and [emim][acetate] $+[\mathrm{emim}][$ trifluoroacetate] mixtures. Journal of Chemical \& Engineering Data 2009, 54, 108-114.

(87) Jung, Y.-H.; Jung, J.-Y.; Jin, Y.-R.; Lee, B.-C.; Baek, I.-H.; Kim, S.-H.: Solubility of carbon dioxide in imidazolium-based ionic liquids with a methanesulfonate anion. Journal of Chemical \& Engineering Data 2012, 57, 3321-3329.

(88) Yim, J.-H.; Lim, J. S.: CO2 solubility measurement in 1-hexyl-3methylimidazolium ([HMIM]) cation based ionic liquids. Fluid Phase Equilibria 2013, 352, 67-74.

(89) Blanchard, L. A.; Gu, Z.; Brennecke, J. F.: High-pressure phase behavior of ionic liquid/CO2 systems. The Journal of Physical Chemistry B 2001, 105, 2437-2444.

(90) Jalili, A. H.; Mehdizadeh, A.; Shokouhi, M.; Ahmadi, A. N.; Hosseini-Jenab, M.; Fateminassab, F.: Solubility and diffusion of $\mathrm{CO} 2$ and $\mathrm{H} 2 \mathrm{~S}$ in the ionic liquid 1-ethyl-3methylimidazolium ethylsulfate. The Journal of Chemical Thermodynamics 2010, 42, 12981303.

(91) Bermejo, M. D.; Fieback, T. M.; Martín, Á.: Solubility of gases in 1-alkyl3 methylimidazolium alkyl sulfate ionic liquids: Experimental determination and modeling. The Journal of Chemical Thermodynamics 2013, 58, 237-244.

(92) Carvalho, P. J.; Álvarez, V. H.; Marrucho, I. M.; Aznar, M.; Coutinho, J. A.: High pressure phase behavior of carbon dioxide in 1-butyl-3-methylimidazolium bis (trifluoromethylsulfonyl) imide and 1-butyl-3-methylimidazolium dicyanamide ionic liquids. The Journal of Supercritical Fluids 2009, 50, 105-111.

(93) Mota-Martinez, M. T.; Althuluth, M.; Kroon, M. C.; Peters, C. J.: Solubility of carbon dioxide in the low-viscosity ionic liquid 1-hexyl-3-methylimidazolium tetracyanoborate. Fluid Phase Equilibria 2012, 332, 35-39.

(94) Chen, Y.; Mutelet, F.; Jaubert, J.-N.: Solubility of CO2 in 1-butyl-3methylimidazolium diethylene-glycolmonomethylethersulfate and trihexyl (tetradecyl) phosphonium dodecyl-benzenesulfonate. Fluid Phase Equilibria 2013, 354, 191-198.

(95) Soriano, A. N.; Doma Jr, B. T.; Li, M.-H.: Solubility of carbon dioxide in 1ethyl-3-methylimidazolium 2-(2-methoxyethoxy) ethylsulfate. The Journal of Chemical Thermodynamics 2008, 40, 1654-1660.

(96) Zhao, Y.; Zhang, X.; Dong, H.; Zhen, Y.; Li, G.; Zeng, S.; Zhang, S.: Solubilities of gases in novel alcamines ionic liquid 2-[2-hydroxyethyl (methyl) amino] ethanol chloride. Fluid phase equilibria 2011, 302, 60-64.

(97) Bermejo, M. D.; Montero, M.; Saez, E.; Florusse, L. J.; Kotlewska, A. J.; Cocero, M. J.; van Rantwijk, F.; Peters, C. J.: Liquid- Vapor Equilibrium of the Systems Butylmethylimidazolium Nitrate- $\mathrm{CO} 2$ and Hydroxypropylmethylimidazolium Nitrate- $\mathrm{CO} 2$ at High Pressure: Influence of Water on the Phase Behavior. The Journal of Physical Chemistry B 2008, 112, 13532-13541.

(98) Carvalho, P. J.; Alvarez, V. H.; Marrucho, I. M.; Aznar, M.; Coutinho, J. A.: High carbon dioxide solubilities in trihexyltetradecylphosphonium-based ionic liquids. The Journal of Supercritical Fluids 2010, 52, 258-265. 
(99) Ramdin, M.; Olasagasti, T. Z.; Vlugt, T. J.; de Loos, T. W.: High pressure solubility of $\mathrm{CO} 2$ in non-fluorinated phosphonium-based ionic liquids. The Journal of Supercritical Fluids 2013, 82, 41-49.

(100) Nwosu, S. O.; Schleicher, J. C.; Scurto, A. M.: High-pressure phase equilibria for the synthesis of ionic liquids in compressed $\mathrm{CO} 2$ for 1-hexyl-3-methylimidazolium bromide with 1-bromohexane and 1-methylimidazole. The Journal of Supercritical Fluids 2009, 51, 1-9.

(101) Hong, G.; Jacquemin, J.; Deetlefs, M.; Hardacre, C.; Husson, P.; Gomes, M. C.: Solubility of carbon dioxide and ethane in three ionic liquids based on the bis \{(trifluoromethyl) sulfonyl $\}$ imide anion. Fluid Phase Equilibria 2007, 257, 27-34.

(102) Manic, M. S.; Queimada, A. J.; Macedo, E. A.; Najdanovic-Visak, V.: Highpressure solubilities of carbon dioxide in ionic liquids based on bis (trifluoromethylsulfonyl) imide and chloride. The Journal of Supercritical Fluids 2012, 65, 1-10.

(103) Yim, J.-H.; Song, H. N.; Lee, B.-C.; Lim, J. S.: High-pressure phase behavior of binary mixtures containing ionic liquid [HMP][Tf2N],[OMP][Tf2N] and carbon dioxide. Fluid phase equilibria 2011, 308, 147-152.

(104) Stevanovic, S.; Podgorsek, A.; Moura, L.; Santini, C.; Padua, A. A.; Gomes, M. C.: Absorption of carbon dioxide by ionic liquids with carboxylate anions. International Journal of Greenhouse Gas Control 2013, 17, 78-88.

(105) Ramdin, M.; Vlugt, T. J.; de Loos, T. W.: Solubility of CO2 in the ionic liquids [TBMN][MeSO4] and [TBMP][MeSO4]. Journal of Chemical \& Engineering Data 2012, 57, 2275-2280.

(106) Palgunadi, J.; Kang, J. E.; Nguyen, D. Q.; Kim, J. H.; Min, B. K.; Lee, S. D.; Kim, H.; Kim, H. S.: Solubility of $\mathrm{CO} 2$ in dialkylimidazolium dialkylphosphate ionic liquids. Thermochimica acta 2009, 494, 94-98.

(107) Carvalho, P. J.; Álvarez, V. H.; Machado, J. J.; Pauly, J.; Daridon, J.-L.; Marrucho, I. M.; Aznar, M.; Coutinho, J. A.: High pressure phase behavior of carbon dioxide in 1-alkyl-3-methylimidazolium bis (trifluoromethylsulfonyl) imide ionic liquids. The Journal of Supercritical Fluids 2009, 48, 99-107.

(108) Ren, W.; Sensenich, B.; Scurto, A. M.: High-pressure phase equilibria of \{carbon dioxide (CO2)+ n-alkyl-imidazolium bis (trifluoromethylsulfonyl) amide\} ionic liquids. The Journal of Chemical Thermodynamics 2010, 42, 305-311.

(109) Karadas, F.; Köz, B.; Jacquemin, J.; Deniz, E.; Rooney, D.; Thompson, J.; Yavuz, C. T.; Khraisheh, M.; Aparicio, S.; Atihan, M.: High pressure CO2 absorption studies on imidazolium-based ionic liquids: Experimental and simulation approaches. Fluid Phase Equilibria 2013, 351, 74-86.

(110) Kim, Y.; Jang, J.; Lim, B.; Kang, J. W.; Lee, C.: Solubility of mixed gases containing carbon dioxide in ionic liquids: Measurements and predictions. Fluid phase equilibria 2007, 256, 70-74.

(111) Shariati, A.; Peters, C.: High-pressure phase behavior of systems with ionic liquids: II. The binary system carbon dioxide+ 1-ethyl-3-methylimidazolium hexafluorophosphate. The Journal of supercritical fluids 2004, 29, 43-48.

(112) Mellein, B. R.; Brennecke, J. F.: Characterization of the ability of $\mathrm{CO} 2$ to act as an antisolvent for ionic liquid/organic mixtures. The Journal of Physical Chemistry B 2007, $111,4837-4843$. 
(113) Yim, J.-H.; Song, H. N.; Yoo, K.-P.; Lim, J. S.: Measurement of CO2 solubility in ionic liquids:[BMP][Tf2N] and [BMP][MeSO4] by measuring bubble-point pressure. Journal of Chemical \& Engineering Data 2011, 56, 1197-1203.

(114) Kim, S. A.; Yim, J.-H.; Lim, J. S.: High-pressure phase behavior of binary mixtures containing methylpyrrolidinium derivative ionic liquids and carbon dioxide. Fluid phase equilibria 2012, 332, 28-34.

(115) Jiang, Y.-Y.; Zhou, Z.; Jiao, Z.; Li, L.; Wu, Y.-T.; Zhang, Z.-B.: SO2 gas separation using supported ionic liquid membranes. The Journal of Physical Chemistry B 2007, $111,5058-5061$.

(116) Huang, J.; Riisager, A.; Berg, R. W.; Fehrmann, R.: Tuning ionic liquids for high gas solubility and reversible gas sorption. Journal of Molecular Catalysis A: Chemical 2008, 279, 170-176.

(117) Anderson, J. L.; Dixon, J. K.; Maginn, E. J.; Brennecke, J. F.: Measurement of SO2 solubility in ionic liquids. The Journal of Physical Chemistry B 2006, 110, 1505915062.

(118) Shiflett, M. B.; Yokozeki, A.: Chemical absorption of sulfur dioxide in roomtemperature ionic liquids. Industrial \& engineering chemistry research 2010, 49, 1370-1377.

(119) Jin, M.; Hou, Y.; Wu, W.; Ren, S.; Tian, S.; Xiao, L.; Lei, Z.: Solubilities and thermodynamic properties of $\mathrm{SO} 2$ in ionic liquids. The Journal of Physical Chemistry B 2011, $115,6585-6591$.

(120) Jalili, A. H.; Rahmati-Rostami, M.; Ghotbi, C.; Hosseini-Jenab, M.; Ahmadi, A. N.: Solubility of H2S in ionic liquids [bmim][PF6],[bmim][BF4], and [bmim][Tf2N]. Journal of Chemical \& Engineering Data 2009, 54, 1844-1849.

(121) Shokouhi, M.; Adibi, M.; Jalili, A. H.; Hosseini-Jenab, M.; Mehdizadeh, A.: Solubility and diffusion of $\mathrm{H} 2 \mathrm{~S}$ and $\mathrm{CO} 2$ in the ionic liquid 1-(2-hydroxyethyl)-3methylimidazolium tetrafluoroborate. Journal of Chemical \& Engineering Data 2010, 55, 1663-1668.

(122) Sakhaeinia, H.; Taghikhani, V.; Jalili, A. H.; Mehdizadeh, A.; Safekordi, A. A.: Solubility of $\mathrm{H} 2 \mathrm{~S}$ in 1-(2-hydroxyethyl)-3-methylimidazolium ionic liquids with different anions. Fluid phase equilibria 2010, 298, 303-309.

(123) Jou, F.-Y.; Mather, A. E.: Solubility of hydrogen sulfide in [bmim][PF 6]. International Journal of Thermophysics 2007, 28, 490.

(124) Sakhaeinia, H.; Jalili, A. H.; Taghikhani, V.; Safekordi, A. A.: Solubility of $\mathrm{H} 2 \mathrm{~S}$ in Ionic Liquids 1-Ethyl-3-methylimidazolium Hexafluorophosphate ([emim][PF6]) and 1-Ethyl-3-methylimidazolium Bis (trifluoromethyl) sulfonylimide ([emim][Tf2N]). Journal of Chemical \& Engineering Data 2010, 55, 5839-5845.

(125) Rahmati-Rostami, M.; Ghotbi, C.; Hosseini-Jenab, M.; Ahmadi, A. N.; Jalili, A. H.: Solubility of $\mathrm{H} 2 \mathrm{~S}$ in ionic liquids [hmim][PF6],[hmim][BF4], and [hmim][Tf2N]. The Journal of Chemical Thermodynamics 2009, 41, 1052-1055.

(126) Safavi, M.; Ghotbi, C.; Taghikhani, V.; Jalili, A. H.; Mehdizadeh, A.: Study of the solubility of $\mathrm{CO} 2, \mathrm{H} 2 \mathrm{~S}$ and their mixture in the ionic liquid 1-octyl-3methylimidazolium hexafluorophosphate: experimental and modelling. The Journal of Chemical Thermodynamics 2013, 65, 220-232.

(127) Jalili, A. H.; Safavi, M.; Ghotbi, C.; Mehdizadeh, A.; Hosseini-Jenab, M.; Taghikhani, V.: Solubility of $\mathrm{CO} 2, \mathrm{H} 2 \mathrm{~S}$, and their mixture in the ionic liquid 1-octyl-3methylimidazolium bis (trifluoromethyl) sulfonylimide. The Journal of Physical Chemistry $B$ 2012, 116, 2758-2774.

(128) Jalili, A. H.; Shokouhi, M.; Maurer, G.; Hosseini-Jenab, M.: Solubility of $\mathrm{CO} 2$ and $\mathrm{H} 2 \mathrm{~S}$ in the ionic liquid 1-ethyl-3-methylimidazolium tris (pentafluoroethyl) trifluorophosphate. The Journal of Chemical Thermodynamics 2013, 67, 55-62.

(129) Yokozeki, A.; Shiflett, M. B.: Ammonia solubilities in room-temperature ionic liquids. Industrial \& engineering chemistry research 2007, 46, 1605-1610. 
(130) Li, G.; Zhou, Q.; Zhang, X.; Zhang, S.; Li, J.: Solubilities of ammonia in basic imidazolium ionic liquids. Fluid Phase Equilibria 2010, 297, 34-39.

(131) WeiJia, S.; Li, D.: The measurement of ammonia solubility in the ionic liquid 1, 3-dimethylimidazolium dimethylphosphate (DMP). Journal of Beijing University of Chemical Technology (Natural Science Edition) 2012, 4.

(132) Revelli, A.-L.; Mutelet, F.; Jaubert, J.-N.: Reducing of nitrous oxide emissions using ionic liquids. The Journal of Physical Chemistry B 2010, 114, 8199-8206.

(133) Shiflett, M. B.; Niehaus, A. M. S.; Yokozeki, A.: Separation of N2O and CO2 using room-temperature ionic liquid [bmim][BF4]. The Journal of Physical Chemistry B 2011, $115,3478-3487$.

(134) Stevanovic, S.; Gomes, M. C.: Solubility of carbon dioxide, nitrous oxide, ethane, and nitrogen in 1-butyl-1-methylpyrrolidinium and trihexyl (tetradecyl) phosphonium tris (pentafluoroethyl) trifluorophosphate (eFAP) ionic liquids. The Journal of Chemical Thermodynamics 2013, 59, 65-71.

(135) Shiflett, M. B.; Niehaus, A. M. S.; Elliott, B. A.; Yokozeki, A.: Phase Behavior of $\mathrm{N} 2 \mathrm{O}$ and $\mathrm{CO} 2$ in Room-Temperature Ionic Liquids [bmim] [Tf $2 \mathrm{~N}]$, [bmim][BF 4],[bmim] [N (CN) 2],[bmim][Ac],[eam][NO 3], and [bmim][SCN]. International Journal of Thermophysics 2012, 33, 412-436.

(136) Chen, Y.; Mutelet, F.; Jaubert, J.-N.: Solubility of carbon dioxide, nitrous oxide and methane in ionic liquids at pressures close to atmospheric. Fluid Phase Equilibria 2014, 372, 26-33.

(137) Kumełan, J.; Kamps, Á. P.-S.; Tuma, D.; Maurer, G.: Solubility of the single gases $\mathrm{H} 2$ and $\mathrm{CO}$ in the ionic liquid [bmim][CH3SO4]. Fluid phase equilibria 2007, 260, 38.

(138) Kumełan, J.; Kamps, Á. P.-S.; Tuma, D.; Maurer, G.: Solubility of CO in the ionic liquid [bmim][PF6]. Fluid phase equilibria 2005, 228, 207-211.

(139) Jacquemin, J.; Husson, P.; Majer, V.; Gomes, M. F. C.: Low-pressure solubilities and thermodynamics of solvation of eight gases in 1-butyl-3-methylimidazolium hexafluorophosphate. Fluid Phase Equilibria 2006, 240, 87-95.

(140) Florusse, L.; Raeissi, S.; Peters, C.: An IUPAC task group study: the solubility of carbon monoxide in [hmim][Tf2N] at high pressures. Journal of Chemical \& Engineering Data 2011, 56, 4797-4799.

(141) Anderson, J. L.; Dixon, J. K.; Brennecke, J. F.: Solubility of CO2, CH4, C2H6, $\mathrm{C} 2 \mathrm{H} 4, \mathrm{O} 2$, and $\mathrm{N} 2$ in 1-Hexyl-3-methylpyridinium Bis (trifluoromethylsulfonyl) imide: Comparison to Other Ionic Liquids. Accounts of chemical research 2007, 40, 1208-1216.

(142) Yuan, X.; Zhang, S.; Chen, Y.; Lu, X.; Dai, W.; Mori, R.: Solubilities of gases in 1, 1, 3, 3-tetramethylguanidium lactate at elevated pressures. Journal of Chemical \& Engineering Data 2006, 51, 645-647.

(143) Liu, X.; He, M.; Lv, N.; Xu, H.; Bai, L.: Selective absorption of CO2 from $\mathrm{H} 2$, $\mathrm{O} 2$ and $\mathrm{N} 2$ by 1-hexyl-3-methylimidazolium tris (pentafluoroethyl) trifluorophosphate. The Journal of Chemical Thermodynamics 2016, 97, 48-54.

(144) Bahadur, I.; Osman, K.; Coquelet, C.; Naidoo, P.; Ramjugernath, D.: Solubilities of carbon dioxide and oxygen in the ionic liquids methyl trioctyl ammonium bis (trifluoromethylsulfonyl) imide, 1-butyl-3-methyl imidazolium bis (trifluoromethylsulfonyl) imide, and 1-butyl-3-methyl imidazolium methyl sulfate. The Journal of Physical Chemistry B 2015, 119, 1503-1514. 
(145) Kumełan, J.; Pérez-Salado Kamps, Á.; Tuma, D.; Maurer, G.: Solubility of H2 in the ionic liquid [bmim][PF6]. Journal of Chemical \& Engineering Data 2006, 51, 1114.

(146) Kumełan, J.; Tuma, D.; Pérez-Salado Kamps, A. 1.; Maurer, G.: Solubility of the single gases carbon dioxide and hydrogen in the ionic liquid [bmpy][Tf2N]. Journal of Chemical \& Engineering Data 2010, 55, 165-172.

(147) Raeissi, S.; Peters, C. J.: Understanding temperature dependency of hydrogen solubility in ionic liquids, including experimental data in [bmim][Tf2N]. AIChE journal 2012, $58,3553-3559$.

(148) Jacquemin, J.; Husson, P.; Majer, V.; Padua, A. A.; Gomes, M. F. C.: Thermophysical properties, low pressure solubilities and thermodynamics of solvation of carbon dioxide and hydrogen in two ionic liquids based on the alkylsulfate anion. Green Chemistry 2008, 10, 944-950.

(149) Kumełan, J.; Pérez-Salado Kamps, Á.; Tuma, D.; Maurer, G.: Solubility of the single gases methane and xenon in the ionic liquid [bmim][CH3SO4]. Journal of Chemical \& Engineering Data 2007, 52, 2319-2324.

(150) Althuluth, M.; Kroon, M. C.; Peters, C. J.: Solubility of methane in the ionic liquid 1-ethyl-3-methylimidazolium tris (pentafluoroethyl) trifluorophosphate. Industrial \& engineering chemistry research 2012, 51, 16709-16712.

(151) Raeissi, S.; Peters, C.: High pressure phase behaviour of methane in 1-butyl3-methylimidazolium bis (trifluoromethylsulfonyl) imide. Fluid phase equilibria 2010, 294, $67-71$.

(152) Kumełan, J.; Pérez-Salado Kamps, Á.; Tuma, D.; Maurer, G.: Solubility of the single gases methane and xenon in the ionic liquid [hmim][Tf2N]. Industrial \& engineering chemistry research 2007, 46, 8236-8240.

(153) Mirzaei, M.; Mokhtarani, B.; Badiei, A.; Sharifi, A.: Solubility of carbon dioxide and methane in 1-hexyl-3-methylimidazolium nitrate ionic liquid, experimental and thermodynamic modeling. The Journal of Chemical Thermodynamics 2018, 122, 31-37.

(154) Costa Gomes, M.: Low-pressure solubility and thermodynamics of solvation of carbon dioxide, ethane, and hydrogen in 1-hexyl-3-methylimidazolium bis (trifluoromethylsulfonyl) amide between temperatures of $283 \mathrm{~K}$ and $343 \mathrm{~K}$. Journal of Chemical \& Engineering Data 2007, 52, 472-475.

(155) Florusse, L. J.; Raeissi, S.; Peters, C. J.: High-pressure phase behavior of ethane with 1-hexyl-3-methylimidazolium bis (trifluoromethylsulfonyl) imide. Journal of Chemical \& Engineering Data 2008, 53, 1283-1285.

(156) Fallanza, M.; Ortiz, A.; Gorri, D.; Ortiz, I.: Propylene and propane solubility in imidazolium, pyridinium, and tetralkylammonium based ionic liquids containing a silver salt. Journal of Chemical \& Engineering Data 2013, 58, 2147-2153.

(157) Lei, Z.; Dai, C.; Chen, B.: Gas solubility in ionic liquids. Chemical reviews 2013, 114, 1289-1326.

\section{Appendix : Ionic liquids covered in the UNIFAC-IL-Gas model}

\begin{tabular}{ll}
\hline Abbreviation & Full name \\
\hline$[$ EMIM $]\left[\mathrm{Tf}_{2} \mathrm{~N}\right]$ & 1-ethyl-3-methylimidazolium bis(trifluoromethylsulfonyl)imide \\
{$[\mathrm{BMIM}]\left[\mathrm{Tf}_{2} \mathrm{~N}\right]$} & 1-butyl-3-methylimidazolium bis(trifluoromethylsulfonyl)imide \\
{$\left[\mathrm{C}_{5} \mathrm{MIM}\right]\left[\mathrm{Tf}_{2} \mathrm{~N}\right]$} & 1-methyl-3-pentylimidazolium bis(trifluoromethylsulfonyl)imide \\
{$[\mathrm{HMIM}]\left[\mathrm{Tf}_{2} \mathrm{~N}\right]$} & 1-hexyl-3-methylimidazolium bis(trifluoromethylsulfonyl)imide \\
{$[\mathrm{OMIM}]\left[\mathrm{Tf}_{2} \mathrm{~N}\right]$} & 1-methyl-3-octylimidazolium bis(trifluoromethylsulfonyl)imide \\
{$[\mathrm{HMMIM}]\left[\mathrm{Tf}_{2} \mathrm{~N}\right]$} & 1-hexyl-2,3-dimethylimidazolium bis(trifluoromethylsulfonyl)imide \\
{$[\mathrm{HEMIM}]\left[\mathrm{Tf}_{2} \mathrm{~N}\right]$} & 1-(2-hydroxyethyl)-3-methyl-imidazolium bis(trifluoromethylsulfonyl)imide \\
\hline
\end{tabular}




\begin{tabular}{|c|c|}
\hline$\left[(\mathrm{OH})_{2} \mathrm{IM}\right]\left[\mathrm{Tf}_{2} \mathrm{~N}\right]$ & 1,3-dihydroxyimidazolium bis(trifluoromethylsulfonyl)imide \\
\hline$\left[(\mathrm{ETO})_{2} \mathrm{IM}\right][\mathrm{Tf} 2 \mathrm{~N}]$ & 1,3-diethoxyimidazolium bis(trifluoromethylsulfonyl)imide \\
\hline$\left[\mathrm{MTOC}_{2} \mathrm{MIM}\right]\left[\mathrm{Tf}_{2} \mathrm{~N}\right]$ & 1-(2-methoxyethyl)-3-methyl-imidazolium bis(trifluoromethylsulfonyl)imide \\
\hline$[\mathrm{EMIM}]\left[\mathrm{BF}_{4}\right]$ & 1-ethyl-3-methylimidazolium tetrafluoroborate \\
\hline$[\mathrm{BMIM}]\left[\mathrm{BF}_{4}\right]$ & 1-butyl-3-methylimidazolium tetrafluoroborate \\
\hline$[\mathrm{HMIM}]\left[\mathrm{BF}_{4}\right]$ & 1-hexyl-3-methylimidazolium tetrafluoroborate \\
\hline$[\mathrm{OMIM}]\left[\mathrm{BF}_{4}\right]$ & 1-methyl-3-octylimidazolium tetrafluoroborate \\
\hline$[\mathrm{HEMIM}]\left[\mathrm{BF}_{4}\right]$ & 1-(2-hydroxyethyl)-3-methyl-imidazolium tetrafluoroborate \\
\hline$[\mathrm{EMIM}]\left[\mathrm{PF}_{6}\right]$ & 1-ethyl-3-methylimidazolium hexafluorophosphate \\
\hline$[\mathrm{BMIM}]\left[\mathrm{PF}_{6}\right]$ & 1-butyl-3-methylimidazolium hexafluorophosphate \\
\hline$[\mathrm{HMIM}]\left[\mathrm{PF}_{6}\right]$ & 1-hexyl-3-methylimidazolium hexafluorophosphate \\
\hline$[\mathrm{OMIM}]\left[\mathrm{PF}_{6}\right]$ & 1-methyl-3-octylimidazolium hexafluorophosphate \\
\hline$[\mathrm{HEMIM}]\left[\mathrm{PF}_{6}\right]$ & 1-(2-hydroxyethyl)-3-methyl-imidazolium hexafluorophosphate \\
\hline $\mathrm{MTOC}_{2} \mathrm{MIM}\left[\mathrm{PF}_{6}\right]$ & 1-(2-methoxyethyl)-3-methyl-imidazolium hexafluorophosphate \\
\hline$[\mathrm{MMIM}]\left[\mathrm{MeSO}_{3}\right]$ & 1,3-dimethylimidazolium methylsulfonate \\
\hline$[\mathrm{EMIM}]\left[\mathrm{MeSO}_{3}\right]$ & 1-ethyl-3-methylimidazolium methylsulfonate \\
\hline$[\mathrm{BMIM}]\left[\mathrm{MeSO}_{3}\right]$ & 1-butyl-3-methylimidazolium methylsulfonate \\
\hline$[\mathrm{HMIM}]\left[\mathrm{MeSO}_{3}\right]$ & 1-hexyl-3-methylimidazolium methylsulfonate \\
\hline$[\mathrm{EMIM}]\left[\mathrm{MeSO}_{4}\right]$ & 1-ethyl-3-methylimidazolium methylsulfate \\
\hline$[\mathrm{BMIM}]\left[\mathrm{MeSO}_{4}\right]$ & 1-butyl-3-methylimidazolium methylsulfate \\
\hline$[\mathrm{HMIM}]\left[\mathrm{MeSO}_{4}\right]$ & 1-hexyl-3-methylimidazolium methylsulfate \\
\hline$\left[\mathrm{EMIM}_{[}\left[\mathrm{EtSO}_{4}\right]\right.$ & 1-ethyl-3-methylimidazolium ethylsulfate \\
\hline$[\mathrm{BMIM}]\left[\mathrm{EtSO}_{4}\right]$ & 1-butyl-3-methylimidazolium ethylsulfate \\
\hline$[\mathrm{HMIM}]\left[\mathrm{EtSO}_{4}\right]$ & 1-hexyl-3-methylimidazolium ethylsulfate \\
\hline$[\mathrm{EMIM}][\mathrm{TFA}]$ & 1-ethyl-3-methylimidazolium trifluoroacetate \\
\hline$[\mathrm{BMIM}][\mathrm{TFA}]$ & 1-butyl-3-methylimidazolium trifluoroacetate \\
\hline [HMIM][TFA] & 1-hexyl-3-methylimidazolium trifluoroacetate \\
\hline$[\mathrm{EMIM}][\mathrm{TfO}]$ & 1-ethyl-3-methylimidazolium trifluoromethanesulfonate \\
\hline$[\mathrm{BMIM}][\mathrm{TfO}]$ & 1-butyl-3-methylimidazolium trifluoromethanesulfonate \\
\hline [HMIM][TfO] & 1-hexyl-3-methylimidazolium trifluoromethanesulfonate \\
\hline [HEMIM][TfO] & 1-(2-hydroxyethyl)-3-methyl-imidazolium trifluoromethanesulfonate \\
\hline$[\mathrm{MMIM}][\mathrm{DMP}]$ & 1,3-dimethylimidazolium dimethylphosphate \\
\hline [EMIM][DMP] & 1-ethyl-3-methylimidazolium dimethylphosphate \\
\hline$[\mathrm{BMIM}][\mathrm{DMP}]$ & 1-butyl-3-methylimidazolium dimethylphosphate \\
\hline [HMIM][DMP] & 1-hexyl-3-methylimidazolium dimethylphosphate \\
\hline$[\mathrm{EMIM}][\mathrm{DCA}]$ & 1-ethyl-3-methylimidazolium dicyanamide \\
\hline$[\mathrm{BMIM}][\mathrm{DCA}]$ & 1-butyl-3-methylimidazolium dicyanamide \\
\hline$[\mathrm{HMIM}][\mathrm{DCA}]$ & 1-hexyl-3-methylimidazolium dicyanamide \\
\hline [EMIM][TCB] & 1-ethyl-3-methylimidazolium tetracyanoborate \\
\hline
\end{tabular}




\begin{tabular}{|c|c|}
\hline [BMIM][TCB] & 1-butyl-3-methylimidazolium tetracyanoborate \\
\hline [HMIM][TCB] & 1-hexyl-3-methylimidazolium tetracyanoborate \\
\hline$[\mathrm{EMIM}]\left[\mathrm{C}_{3} \mathrm{~F}_{7} \mathrm{CO}_{2}\right]$ & 1-ethyl-3-methylimidazolium heptafluorobutyrate \\
\hline$[\mathrm{BMIM}]\left[\mathrm{C}_{3} \mathrm{~F}_{7} \mathrm{CO}_{2}\right]$ & 1-butyl-3-methylimidazolium heptafluorobutyrate \\
\hline$[\mathrm{HMIM}]\left[\mathrm{C}_{3} \mathrm{~F}_{7} \mathrm{CO}_{2}\right]$ & 1-hexyl-3-methylimidazolium heptafluorobutyrate \\
\hline$[\mathrm{EMIM}]\left[\mathrm{NO}_{3}\right]$ & 1-ethyl-3-methylimidazolium nitrate \\
\hline$[\mathrm{BMIM}]\left[\mathrm{NO}_{3}\right]$ & 1-butyl-3-methylimidazolium nitrate \\
\hline$[\mathrm{HMIM}]\left[\mathrm{NO}_{3}\right]$ & 1-hexyl-3-methylimidazolium nitrate \\
\hline$\left[\right.$ EMIM] $\left[\mathrm{MDEGSO}_{4}\right]$ & 1-ethyl-3-methylimidazolium 2-(2-methoxyethoxy)ethylsulfate \\
\hline$[\mathrm{BMIM}]\left[\mathrm{MDEGSO}_{4}\right]$ & 1-butyl-3-methylimidazolium 2-(2-methoxyethoxy)ethylsulfate \\
\hline$[\mathrm{HMIM}]\left[\mathrm{MDEGSO}_{4}\right]$ & 1-hexyl-3-methylimidazolium 2-(2-methoxyethoxy)ethylsulfate \\
\hline$[\mathrm{HMIM}][\mathrm{Cl}]$ & 1-hexyl-3-methylimidazolium chloride \\
\hline [EMIM][Br] & 1-ethyl-3-methylimidazolium bromide \\
\hline$[\mathrm{BMIM}][\mathrm{Br}]$ & 1-butyl-3-methylimidazolium bromide \\
\hline$[\mathrm{HMIM}][\mathrm{Br}]$ & 1-hexyl-3-methylimidazolium bromide \\
\hline [EMIM][eFAP] & 1-ethyl-3-methylimidazolium tris(pentafluoroethyl)trifluorophosphate \\
\hline [BMIM][eFAP] & 1-butyl-3-methylimidazolium tris(pentafluoroethyl)trifluorophosphate \\
\hline [HMIM][eFAP] & 1-hexyl-3-methylimidazolium tris(pentafluoroethyl)trifluorophosphate \\
\hline [EMIM][SAC] & 1-ethyl-3-methylimidazolium saccharinate \\
\hline$[\mathrm{BMIM}][\mathrm{SAC}]$ & 1-butyl-3-methylimidazolium saccharinate \\
\hline$[\mathrm{HMIM}][\mathrm{SAC}]$ & 1-hexyl-3-methylimidazolium saccharinate \\
\hline$[\mathrm{EMIM}][\mathrm{SUC}]$ & 1-ethyl-3-methylimidazolium succinamate \\
\hline$[\mathrm{HMIM}][\mathrm{SUC}]$ & 1-butyl-3-methylimidazolium succinamate \\
\hline [BMIM][SUC] & 1-hexyl-3-methylimidazolium succinamate \\
\hline [BMIM][TFES] & 1-ethyl-3-methylimidazolium tetrafluoroethanesulfonate \\
\hline$[$ EMIM] $[$ TFES $]$ & 1-butyl-3-methylimidazolium tetrafluoroethanesulfonate \\
\hline [HMIM][TFES] & 1-hexyl-3-methylimidazolium tetrafluoroethanesulfonate \\
\hline [BMIM][LEV] & 1-ethyl-3-methylimidazolium levulinate \\
\hline [EMIM][LEV] & 1-butyl-3-methylimidazolium levulinate \\
\hline [HMIM][LEV] & 1-hexyl-3-methylimidazolium levulinate \\
\hline$[\mathrm{EMPY}]\left[\mathrm{Tf}_{2} \mathrm{~N}\right]$ & 1-ethyl-3-methylpyridinium bis(trifluoromethylsulfonyl)imide \\
\hline$[\mathrm{BMPY}]\left[\mathrm{Tf}_{2} \mathrm{~N}\right]$ & 1-butyl-3-methylpyridinium bis(trifluoromethylsulfonyl)imide \\
\hline$[\mathrm{HMPY}]\left[\mathrm{Tf}_{2} \mathrm{~N}\right]$ & 1-hexyl-3-methylpyridinium bis(trifluoromethylsulfonyl)imide \\
\hline$[\mathrm{BPY}]\left[\mathrm{BF}_{4}\right]$ & 1-butylpyridinium tetrafluoroborate \\
\hline$[\mathrm{EMPYR}]\left[\mathrm{Tf}_{2} \mathrm{~N}\right]$ & 1-ethyl-1-methylpyrrolidinium bis(trifluoromethylsulfonyl)imide \\
\hline$\left[\mathrm{C}_{3} \mathrm{MPYR}\right]\left[\mathrm{Tf}_{2} \mathrm{~N}\right]$ & 1-methyl-1-propylpyrrolidinium bis(trifluoromethylsulfonyl)imide \\
\hline$[\mathrm{BMPYR}]\left[\mathrm{Tf}_{2} \mathrm{~N}\right]$ & 1-butyl-1-methylpyrrolidinium bis(trifluoromethylsulfonyl)imide \\
\hline$\left[\mathrm{C}_{5} \mathrm{MPYR}\right]\left[\mathrm{Tf}_{2} \mathrm{~N}\right]$ & 1-methyl-1-pentylpyrrolidinium bis(trifluoromethylsulfonyl)imide \\
\hline$[\mathrm{HMPYR}]\left[\mathrm{Tf}_{2} \mathrm{~N}\right]$ & 1-hexyl-1-methylpyrrolidinium bis(trifluoromethylsulfonyl)imide \\
\hline$\left[\mathrm{C}_{7} \mathrm{MPYR}\right]\left[\mathrm{Tf}_{2} \mathrm{~N}\right]$ & 1-heptyl-1-methylpyrrolidinium bis(trifluoromethylsulfonyl)imide \\
\hline$[\mathrm{OMPYR}]\left[\mathrm{Tf}_{2} \mathrm{~N}\right]$ & 1-methyl-1-octylpyrrolidinium bis(trifluoromethylsulfonyl)imide \\
\hline [BMPYR][eFAP] & 1-butyl-1-methylpyrrolidinium tris(pentafluoroethyl)trifluorophosphate \\
\hline [BMPYR][LEV] & 1-butyl-1-methylpyrrolidinium levulinate \\
\hline$[\mathrm{N} 1,1,3,2-\mathrm{OH}]\left[\mathrm{Tf}_{2} \mathrm{~N}\right]$ & 2-hydroxyethyltrimethylammonium bis(trifluoromethylsulfonyl)imide \\
\hline
\end{tabular}




\begin{tabular}{ll}
\hline$[\mathrm{N} 1,8,8,8]\left[\mathrm{Tf}_{2} \mathrm{~N}\right]$ & $\mathrm{N}$-methyl-N,N,N-trioctylammonium bis(trifluoromethylsulfonyl)imide \\
{$[\mathrm{N} 4,1,1,1]\left[\mathrm{Tf}_{2} \mathrm{~N}\right]$} & $\mathrm{N}$-butyl-N,N,N-trimethylammonium bis(trifluoromethylsulfonyl)imide \\
{$[\mathrm{MDEA}][\mathrm{Cl}]$} & 2-[2-hydroxyethyl (methyl) amino]ethanol chloride \\
{$[\mathrm{TDPh}]\left[\mathrm{Tf}_{2} \mathrm{~N}\right]$} & trihexyl tetradecyl phosphonium bis(trifluoromethylsulfonyl)imide \\
{$[\mathrm{TDPh}][\mathrm{Br}]$} & trihexyl tetradecyl phosphonium bromide \\
{$[\mathrm{TDPh}][\mathrm{eFAP}]$} & trihexyl tetradecyl phosphonium tris(pentafluoroethyl)trifluorophosphate \\
{$[\mathrm{TDPh}][\mathrm{phos}]$} & trihexyl tetradecyl phosphonium bis(2,4,4-trime-thylpentyl)phosphinate \\
{$[\mathrm{P} 1,4,4,4]\left[\mathrm{MeSO}_{4}\right]$} & tributyl methyl phosphonium methylsulfate \\
{$[\mathrm{P} 1,4,4,4][\mathrm{TOS}]$} & tributyl methyl phosphonium p-toluenesulfonate \\
{$[\mathrm{TMG}][\mathrm{L}]$} & $1,1,3,3$-tetramethyl-guanidium lactate \\
\hline
\end{tabular}

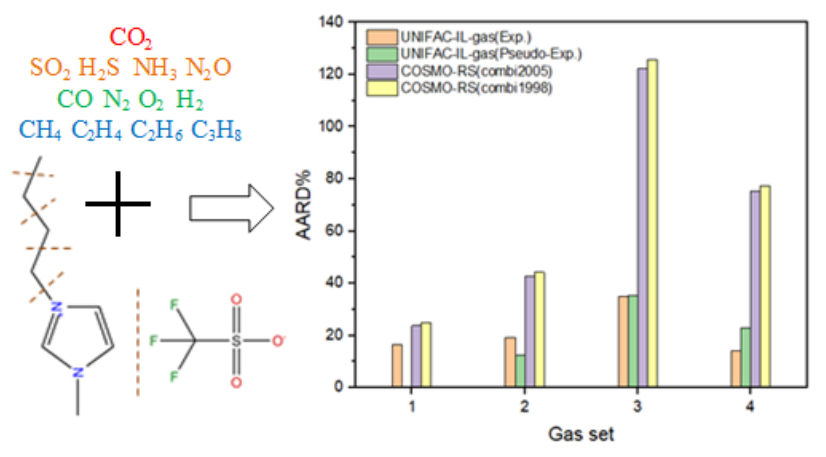


For Table of Contents Only 